LA- $-9438-$ MS

DE83 003988
LA-9438-MS

(ISP0-172)

UC-15

Issued: October $1952^{2}$

\title{
Nondestructive Verification with Minimal Movement of Irradiated Light-Water-Reactor Fuel Assemblies
}

\author{
J. R. Phillips \\ G. E. Bosler \\ J.K. Halbig \\ S. F. Klosterbuer \\ H. O. Menlove
}

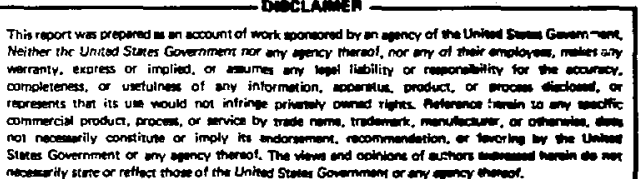

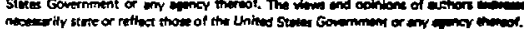

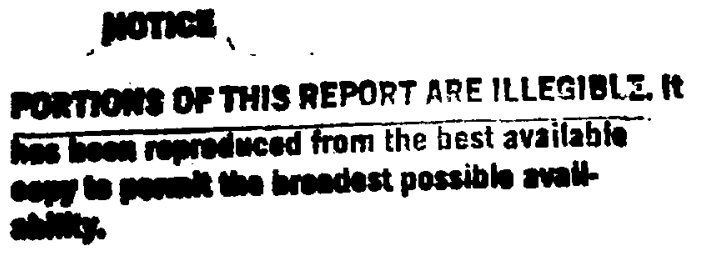


CONTENTS

ABSTRACT . . . . . . . . . . . . . . . . . . . 1

I. INTRODUCTION ................... 1

II. LEVELS OF VERIFICATION . . . . . . . . . . . . . 4

A. Indication of Irradiation Exposure . . . . . . . . 4

1. Cerenkov Glow Intensity Measurement ... . . . 4

2. Gross Gamna-Ray Measurements . . . . . . . 6

3. Neutron Measurements . . . . . . . . . 7

B. Physical Integrity of a Fuel Assembly . . . . . . . 7

1. Cerenkov Glow Intensity Measurement . . . . . . 7

2. Gross Gamma-Ray Measurements . . . . . . . . 7

C. Presence of Fission Products and Actinides....... . 8

D. Relative Concentrations of Fission Products and

Actinides ................ . . 10

1. Fission Products................ 10

2. Actinide Concentrations ....... . . . 13

E. Direct Measurement of Special Nuclear Material . . . 13

III. EXPERIMENTAL MEASUREMENTS . . . . . . . . . . 14

IV. NEUTRON MEASUREMENTS ................. 18

A. Evaluation of the Square-Ring Detector Using

Calibrated Sources . . . . . . . . . . 18

B. Evaluation of the Square-Ring Detector Using

a Simulated Fuel Assembly ............ 20

C. Measurement of Irradiated PWR Fuel Assemblies . . . 23

1. Relationship Between Neutron Emission Rate and Exposure............... 25

2. Reproducibility Measurements ........... 26

3. Variability in Source Strength at One Axial Location . . . . . . . . . . . . . 26

4. Axial Neutron Profiles ............. 31 
5. Correlation Between Measured Neutron Rates and Declared Exposures . . . . . . . . . 33

6. Position Sensitivity for the Square-Ring Detector 38

v. GROSS GAMMA MEASUREMENTS ................ 40

A. Origins of Gross Gamma-Ray Sources . . . . . . . 40

B. Reproducibility Measurements............40

C. Variability in Source Strength at One Axial Location . . 42

D. Axial Gross Gamma-Ray Profiles . . . . . . . . . 43

E. Correlation Between Declared Cooling Times and Measured Doses . . . . . . . . . . . . . . 43

F. Position Sensitivity for the Square-Ring Detector . •. 46

VI. CONCLUSIONS AND RECOMMENDATIONS ............ 48 ACKNOWLEDGMENTS ...................... 53 REFERENCES ......................... 53 
1. Relative neutron source rates for each of the five largest contributors to the total neutron rate . . . . . . . . . . . . . . . . . 11

2. Neutron source rate as a function of exposure for four cooling

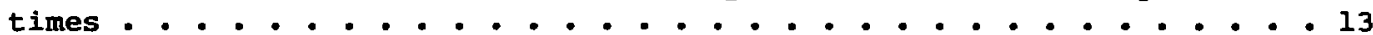

3. Calculated response of dose divided by exposure as a function of cooling time for PWR fuel assemblies . . . . . . . . . . . . . . . . . 15

4. Components of the square-ring detector . . . . . . . . . . . . . . . 15

5. Square-ring detector and an irradiated PWR fuel assembly . . . . . . 16

6. Locating assembly with detector tube . . . . . . . . . . . . . 17

7. Relative position of fuel assembly and detector tube and detector package used in V-detector . . . . . . . . . . . . . . 17

8. PWR fuel assembly located in positioning assembly for measurement . . . . . . . . . . . . . . . . . . . . . . . . . 18

9. Responses of a calibrated source at specified locations inside the square-ring detector for (a) all four detectors and (b)

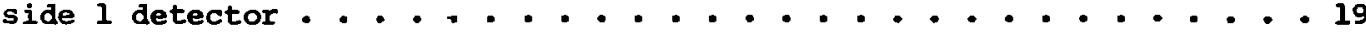

10. Measured response of a source moved perpendicular to the axis

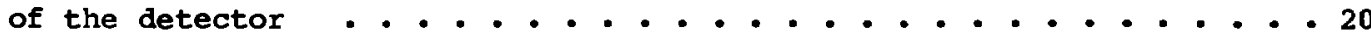

11. Cross section of fuel. assembly used in the simulated source measurements of a $15 \times 15$ PNR fuel assembly . . . . . . . . . . . . . . 21

12. Measured neutron rates (count/s) for the ${ }^{252} \mathrm{Cf}$ in the 21 guide-tube positions for three different measurenent geometries . . • . 22

13. Measured neutron rates for a $252 \mathrm{cf}$ scurce in the center guide-tube position at specified vertical position . . . . . . . . 23

14. Square-ring detector, mounted on support bracket, on top of the PWR storage baskets . . . . . . . . . . . . . . . . . . . 25

15. Measured neutron activities for each side of the 14 irradiated fuel assemblies. The count rates were corrected to time of discharge using the 18.1-yr half-1ife of ${ }^{244} \mathrm{Cm} . . . . . . . .30$

16. Measured neutron activities for each corner of the 14 irradiated fuel assemblies. The count rates were corrected to time

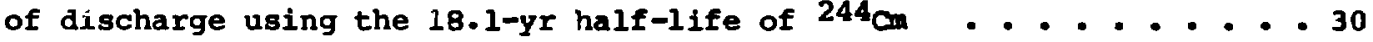

17. Axial neutron profilas for each side of the four fuel assenblies: $A-72(18.47 \mathrm{GNd} / \mathrm{tU}), \mathrm{C}-32$ (23.57 Gd/tU), C-51 (28.90 GWd/tU), and B-52 (31.71 GNd/tU) . . . . . . . . . . . . . . . 32 
18. Measured neutron emission rates using the square-ring detector values vs the operator-declared exposure values for 14 PWR

fuel assemblies ......................... 34

19. Measured neutron emission rates using the $v$-detector values vs the operator-declared exposure values for 14 PWR fuel assem-

blies . . . . . . . . . . . . . . . . . . . . . . 34

20. Measured gross gamma-ray dose rates for each side of the 14

irradiated fuel assemblies . . . . . . . . . . . . . . . 44

21. Measured gross gamma-ray dose rates for each corner of the

14 irradiated fuel assemblies .................44

22. Axial gross garma-ray profile for each side of the four

fuel assemblies: $A-72(18.47 \mathrm{GWd} / \mathrm{tU}), \mathrm{C}-32(23.57 \mathrm{GWd} / \mathrm{tU})$,

$c-51(28.91 \mathrm{GWd} / \mathrm{tU})$, and $\mathrm{B}-52(31.71 \mathrm{GWd} / \mathrm{tU}) \ldots . . . . . . .45$

23. Gross gamma-ray dose/exposures vs cooling time for the set

of 14 fuel assemblies using the square-ring detector (Refer to Fig. 3

for calculated response.).................. 47

24. Gross gamma-ray dose/exposure vs cooling time for the set

of 14 fuel assemblies using the corner V-detector (Refer to Fig. 3

for calculated response.) . . . . . . . . . . . . . . . 47

25. Two detector designs for the rapid verification of spent-

ffuel assemblies . . . . . . . . . . . . . . . . . . 52 
TABIES

I. Ievels of verification for spent-fuel assemblies . . . . . . . . . 3

II. Principal sources of neutrons in irradiated $\mathrm{NO}_{2}$

materials . . . . . . . . . . . . . . . . . . . . . . . 10

III. Percentage of gamma rays from each row based on the

total value . . . . . . . . . . . . . . . . . . . . . . 12

IV. Fuel assembly parameters for $14 \times 14$ array . . . . . . . . . . . . 24

v. Fuel assemblies measured at the vorris Spent-Fuel

storage Facility . . . . . . . . . . . . . . . . . . . . 24

VI. Square-ring reproducibility measurements . . . . . . . . . . . . . . 27

VII. $\quad$ Iong-term reproducibility measurements . . . . . . . . . . . . . . . 28

VIII. Measured neutron results for the square-ring detector . . . . . . 29

IX. Measured neutron results for the corner v-detector . . . . . . . . 31

X. Relative results based on the square-ring measurements . . . . . . 35

XI. Relative results based on the corner V-detector meas-

urements . . . . . . . . . . . . . . . . . . . . . . . . 36

XII. Comparison of the two measurement geometries . . . . . . . . . . 37

XII. Effect of variability in counting rates on calculated

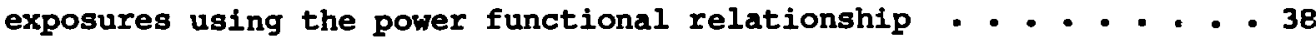

XIV. Position sensitivity for neutron measurements using

the square-ring detector . . . . . . . . . . . . . . . . . . 39

XV. Measurable isotopes in typical INR fuel assemblies . . . . . . . . 4l

XVI. Measured gamma-ray results for the square-ring de-

tector . . . . . . . . . . . . . . . . . . . . . . . . . 42

XVII. Heasured gamma-ray results for the corner V-detector . . . . . . . 43

XVIII. Relative gamma-ray measurements of fuel assemblies . . . . . . . . 48

XIX. Results of cooling time consigtency calculation . . . . . . . . 49

xx. Position sensitivity for gross gamma-ray neasure-

ments using the square-ring detector . . . . . . . . . . . . . . 50 
NONDESTRUCTIVE VERIFICATION WITH MINIMAI MOVEMENT OF IRRADIATED LIGHT-WATER REACTOR FUEL ASSEMBLIES

by

J. R. Phillips, G. E. Bosler, J. K. Halbig, S. F. Klosterbuer, and H. O. Menlove

\begin{abstract}
Nondestructive verification of irradiated light-water reactor fuel assemblies can be performed rapialy and precisely by measuring their gross gamma-ray and neutron signatures. A portable system measured fuel assemblies with expcsures ranging from 18.4 to $40.6 \mathrm{GWd} / \mathrm{tU}$ and with cooling times ranging from 1575 to 2638 days. Differences in the measured results for side or corner measurements are discussed.
\end{abstract}

I. INTRODUCTION

Spent-fuel assemblies are accumulating at an increasingly rapid rate because of delays in nuclear fuel reprocessing. This potential source of very large and growing quantities of plutonium can have undesirable international consequences. 1 The primary objective of international safeguards is the

timely detection of diversion of significant quantities of nuclear material from peaceful nuclear activities to the manufacture of nuclear weapons or of other iuclear explosive devices, or for purposes unknown, and deterrence of such diversion by the risk of early detection. 2 
The International Atomic Energy Agency (IAEA) is committed to the use of material accountancy as a fundamentally important technique for detection of a diversion, with containment and surveillance as important complementary measures.

The plutonium content of spent-fuel assemblies is of primary importance, with the residual ${ }^{235} \mathrm{v}$ content being less significant. The significant quantity (approximate quantity of special nuclear fissionable material required for a single explosive device) for plutonium has been generally accepted as $8 \mathrm{~kg} \cdot{ }^{3}$ This amount is equivalent to the plutonium present in two pressurized-water reactor ( $P W R$ ) or five boiling-water reactor (BWR) fuel assemblies discharged from typical facilities. Another important factor in evaluating the requirements for safeguarding spent-fuel assemblies is the time required to convert the plutonium present in the fuel assembly to a form compatible with the fabrication of a nuclear explosive. Time estimates for this conversion range from 1 to 3 months. 4 At present, the IAEA has established a detection time of a few months for irradiated materials with a desired detection probability of 958.5

To verify the special nucliar material inventory of spent-fuel assemblies in a storage facility, a straightforward sampling plan could determine the number of fuel assemblies to be neasured for the desired level of confidence. An approximate formula ${ }^{6}$ for the detection probability provided by the attribute measurement of fuel assemblies is

$$
D F=1 \cdots(1-f)^{D}
$$

where DP is the desired detection probability, $f$ is the fraction of the total number of fuel assemblies that must be sampled, and $D$ is the number of missing or altered fuel assemblies to be detected. To attain a $95 \%$ detection probability where $D$ is 2 for PWR fuel assemblies and 5 for BWR fuel assenblies, the inspector would be required to select randomly and to measure approximately 808 of the FWR and 45t of the BAR fuel assemblies.

A variety of nondestructive measarement techniques is available for verifying spent-fuel assemblies, depenaing upon the level of verification required. Table I shows the relationship between the various gama-ray and neutron measurement techniques and the specific levels of verification. ${ }^{7}$ in injpector would not necessarily linit himself to elther gama-ray or noutron techniques but might combine the two techniques. 
Specific Level of Verification

Physical characteristics

Indication of irradiation exposure

Physical integrity of fuel assembly

Presence of fission products and actinides

Relative concentrations of fission products and actinides
Nondestructive Technique

Gamma Ray
Cerenkov
Presence of gamma
radiation

Cerenkov

Relative intensities of high-energy ganma rays

Qualitative 1dentification of specific gawmaray ilines

Quantitative moasurement of $137 \mathrm{Cs}$. $13 \mathrm{Ce}_{\mathrm{s}} /{ }^{137} \mathrm{Cs}$, and $154 \mathrm{Lu} / 137 \mathrm{Cs}$. Correlation with operatordeclared information
Presence of neutron radiation

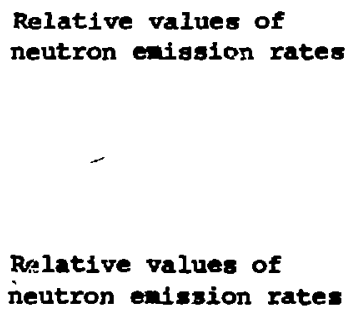

Relative values of neutron eaission rates

Ralative palues of neutron eafsion rates

Quantitative masurewnt of neutron anvion rate. Correlation with operatordeclered information
Instrumentation

Visual inspection

Cerenkov viewing device

Ion chamber:

Thermoluinescent

detectore

Scintillators

Fission chanbers

$10_{\mathrm{B}}$ detectors

Cerenkov vikwing device

Germaniue detectors $\operatorname{Be}(\gamma, n)$ detectors

Fisston chanbers

$10_{B}$ detectors

Germanive detectors $\mathrm{Be}(\gamma, n)$ detectors

Fiseion chambers

$10_{B}$ jetector:

Germaniu detector:

Fieston chmbers

10. detector:
Direct measurcent of opecial nuclear nterial
Indirectly through correlations between KDA wasurements and deetructive analyes guantitative measurenent of induced fiesions in special muclear materiel
Germanium atector:

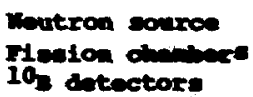


For reactors, the maximum time allocated for routine inspection is onesixth of a man-year for each facility per calendar year. ${ }^{2}$ An inspector cannot devote the entire inspection time to the verification of spent-fuel assemblies. He must review the auditing records and compaxe them with the IAEA reports, exanine operating records and compare them with the accounting records, verify the fresh fuel assemblies before core loading, and verify the number of fuel assemblies in the reactor core following refueling and before closure of the reactor vessel. 4 Therefore, an inspector selects a level of verification consistent with the constraint of available time.

II. LEVELS OF VERIFICATION

A. Indication of Irradiation Exposure

The emission of gama rays from a fuel assembly in the storage rack is a low-level verification. Two gamma-ray measurement techniques are available: (1) Cerenkov glow measurement 8,9 and (2) ion chamber or scintillator ${ }^{10}$ neasurements. The Cerenkov technique has the distinct advantage of performing the verification without placing any instrumentation into the storage pool water. But it has the disadvantage of requiring the elimination of most of the artificial lighting, forcing the inspector to move in a darkened environsent, and increasing the safety hazari.

The gross gamma-ray signature of fuel assemblies also can be measured using ion chambers or scintillators or thermoluminescent detectors (TLD). The signature is primarily from the activation products $\left({ }^{60} \mathrm{Co}, 58 \mathrm{Co}\right.$, and ${ }^{54}$ (n) in the structural material at the top of the fuel assemblies, with the fission products $\left({ }^{134} \mathrm{Cs},{ }^{137} \mathrm{Cs}\right.$, and $\left.{ }^{144} \mathrm{Pr}\right)$ also contributing. Ion chambers and scintiliators provide the information immediately, whereas the THDs must be removed from the water and subsequently reaa with a special instrument.

1. Cerenkov Glow Intensity Neasurement. 8,9 Electromagnetic Cerenkov radiation is emitted whenever a shsrged particle passes through a medium with a velocity exceeding the phase velocity of light in that medium. In water, the phase velocity of light is about $75 \%$ of the value in vacuum. Any electron passing through water and having $20.26 \mathrm{MeV}$ kinetic energy is thus a source of Cerenkov radiation. Irradiated fuel assemblies are prolific sources of bata 
particles, gamma rays, and neutrons, all of which can produce Cerenkov light, directly or indirectly.

The normal fuel pin cladding (0.6- to 0.8-mn-thick zircaloy) will absorb some of the beta particles originating in the fuel material; however, a significant fraction of the beta particles will enter the pool wate= and will be a significant source of Cerenikov light. It is possible that electron brensstrahlung from energetic beta particles interacting in the fuel pins could be a significant source of gamma radiation in the pool water. In the cooling water, energetic fission product gamia rays can undergo pair production or Compton scattering to produce $\geq 0.26-\mathrm{HeV}$ electrons. Neutrons may undergo $\mathrm{H}(\mathrm{n}, \gamma)$ reactions in the water and produce Cerenkov light through interactions of the 2.23-MeV capture gamma rays with water.

The most significant production of Cerenkov light is from high-energy fission fragment-decay gamma rays that penetrate the cladding and fuel and interact with the water. The number of Cerenkov photons generated from gama rays of any energy passing through water can be calculated. These calculations indicate that Cerenkov light production in the visible range of 4000-6000 $A$ is negligible for gamma rays with $\mathrm{E} \leq 0.6 \mathrm{keV}$ and rises steepiy with greater gamma-ray energy. A gama ray with $E=2 \mathrm{MeV}$ produces more than 500 tines the Cerenkov phot ins that are produced by a gama ray with $E=0.6 \mathrm{MeV}$.

The information obtained from a Cerenkov measurement is related to burnup in that the absolute Cerenkov light level and its decay with time are related to burnup. If the Cerenkov light intensity is measured accurately, successful diversion either by substitution of dumny fuel assemblies or by incorrectly stating burnup should be difficult.

The spatial extent of the Cerenkov glow surrounding an isolated irradiated assembly in water probably is determined by the gama radiation from the assembly's outer pins. The one-tenth-value-layer thickness of water for 1.0 -iev gamma rays is $136 \mathrm{~cm}$, which is a reasonable estimate of the Cerenkov "halo" around an isolated point source. Fission product radiation from an irradited fuel assembly's inner pins, however, must penetrate a mach denser composte of fuel, cladding, and interstitial water that greatly reduces crosstalk anong assemblies in either regular or high-density storage racks. The problem of crosstalk becomes significant when the gama-ray field is moasured abov the fuel assemblies using ion chamers or scint1llators (Sec. II. A.2). 
The Cerenkov glow intensity measurement provides the inspector with a rapid nondestructive cechnique for verifying the presence of a gama-ray source distributed within the iuel assembly. Where all the fuel pins can be seen, the inage can be used to determine the removal of fuel pins from the fuel assenbly. If several fuel pins were removed and were replaced with counterfeit fuel pins. an inspector might not detect the substitution. However, we stress that the intensity of the glow depends upon both the time since discharge from the reactor and the total exposure of the fuel assembly. The technique can provide a yalitative measurement for separacing fuel assemblies into secs with siailar gamma-ray source strengths without placing any equipment into the pool water.

2. Gross Gamma-Ray Measurements. 10,11 Ion chambers or scintillator detectors also can be used to verify the presence of gama-ray radiation in spent-fuel assemblies in storage racks. Crosstalk between fuel assemilies 10cated in adjacent storage positions must be reduced to a minimum to avoid the necessity of using unfolding technic es. ${ }^{12}$ mis measurement technique requires that the instrument

(1) be lightweight and easy to position by hand,

(2) give an inmediate result,

(3) be undamaged by high-radiation levels, and

(4) ensure meaningful results.

Using a collinated germanium detector, we have measured the gana-ray spectrum emitted from the top of two PWR fuel assemblies with exposures of 40.1 and $26.9 \mathrm{GNd} / \mathrm{tU}$ and cooling times of 1575 and 2049 days, respectively. The prominent gama-ray lines in the spectrum were from the ${ }^{60} \mathrm{Co},{ }^{137} \mathrm{Cs}$, and ${ }^{134} \mathrm{Cs}$ isotopes, with a very gall contribution from the ${ }^{144} \mathrm{Pr}$ isotope. The long cooling times would have significantly reduced the contribution from 144 Pr, which is the daughter of the 285 -day fission product ${ }^{144} \mathrm{Ce}$. Cesium-137 and ${ }^{134} \mathrm{Cs}$ were dissolved in the pool water; therefore, it was not possible to determine quantitatively how much of the signals from these two isotopes was coming from the specific fuel assembly. The total signal coning from the fuel assembly was very low, as was the signal coning from the cesiu diesolped in the pool water. The pool water was very clean, having much less cesium in it than would normally be expected at reactor spent-fuel storage pools. Cobalt-60 existed as a contaminant in the pool water as well as coning from the structural material of the fuel assemblies. Based upon our monsurcants, we cannot 
confirm how much of the signals measured from the collinated germaniun detector was due to the fission product inventory in the fuel assembly.

Ion chamber and scintillator detection techniques have been demonstrated to distinguish between fuel assemblies having widely differing exposures. They are rapid measurement techniques requiring only 1-2 min for positioning the detectors and collecting the data. For fuel assemblies stored in caniaters, these are the only techniques for rapidly verifying the presence of radioactive material.

3. Neutron Measurements. Present technology does not permit the measurement of the neutron signals of spent-fuel assemblies by placing neutron detectors on top of the storage rack. The neutron flux, reduced by a factor of 10 for each $10 \mathrm{~cm}$ of water, ${ }^{13}$ and the fuel material, located approximately $50 \mathrm{~cm}$ below the top of the storage racks, reduced the neutron source below the sensitivity level of most neutron detectors.

B. Physical Integrity of a Fuel Assembly

1. Cerenkov Glow Intensity seasurenent. As discussed in Sec. II.A.1, this measurement technique has been used to determine the removal of individual fuel pins by examining the image and detecting anomalies in the glow pattern. For fuel assemblies with top plates, the fuel pins nay not be viaible; therefore, the technique is not fail safe.

2. Gross Gamma-Ray Measurements. Measurement of gross gama-ray signal. above fuel asserablies in a storage rack can detect only very large changes in the number of fuel pins present. However, removing the fuel assembly from the storage rack, that $1 \mathrm{~s}$, raising the assembly so measurements can be made from the side, significantly inproves the detectability of fuel pin removal. In either measurement geometry, because of the source self-attenuation, the datectors only measure the gana-ray signal from fuel pins located on the periphery of the fuel assembly.

The gamna-ray neasureaents can be improved by using a Be $(\gamma, n)$ detector in which a ${ }^{235} \mathrm{U}$ fisetion chamber 1s surrounded by successive annuli of polyethylene and beryllium. Neutrons produced by a photoneutron reaction in the berylliv are thermalized in the polyethylene and then counted by the $235 \mathrm{v}$ fiseion 
chamber. Because the threshold for photoneutron production in beryllium is $1.66 \mathrm{MeV}$, the only significant fission product with a higher gama-ray energy is the $2.186 \mathrm{MeV}$ gamma ray of ${ }^{144} \mathrm{Pr}$. The ${ }^{144} \mathrm{Pr}$ isotope, with a short half-life $\left(t_{1 / 2}=17.3 \mathrm{~min}\right)$ is in secular equilibrium with its parent ${ }^{144} \mathrm{Ce} / t_{1 / 2}=$ 284.5 days). Therefore, the $\operatorname{Be}(\gamma, n)$ detector measures the relative activity of $144 \mathrm{Ce}$.

The penetrability of the $2.186 \mathrm{MeV}$ garma ray is considerably greater than that of the majority of gamma rays from fission products ( $20.6 \mathrm{MeV})$. Even the inner pins of a PWR fuel assembly can contribute to the 2.186-MeV source strength. For example, the fuel pins of the center row in the $15 \times 15$ fuel array can contribute 48 of the total flux of $2.186-\mathrm{Mev}$ gama rays at the surface of a fuel assembly, whereas for a $0.6-\mathrm{MeV}$ gamma ray the self-attenuation has reduced its contribution to essentially 0.0 . This measurement technique using a $B e(\gamma, n)$ detector is not fail proof, but it is better than just measuring the gross gamma-ray signal with an ion chamber or scintillator to determine the absence of fuel pins.

C. Presence of Fission Products and Actinides

The presence of fission products can be detected only by using instrumentation that allows some type of energy resolution. The gama-ray signatures of actinides cannot be measured directly because of the relatively high fission product background. A Be $(\gamma, n)$ detector can be used to detect the presence of gamma rays with energies above $1.66 \mathrm{MeV}$ and to infer the presence of the fission product ${ }^{144} \mathrm{Pr}$. High-resolution gamma spectrometry (HRGS) using a germanium detector is the preferable technique for determining the presence of fission products. A spectrum obtained by HRGs can be used to qualitatively identify the source material by the comparison of the relative intensities of specific fission products. For example, the relative intensities of ${ }^{106}{ }_{R h}$ and ${ }^{137}$ Cs can be used to identify qualitatively if the source material were ${ }^{235} \mathrm{U}$ or ${ }^{239} \mathrm{Pu}$, because of the differences in the fission yields for ${ }^{106} \mathrm{Ru}-\mathrm{Rh}$ $\left(0.48\right.$ for ${ }^{235} \mathrm{U}$ and 4.38 for $\left.{ }^{239} \mathrm{Pu}\right)$. Information about the tine since discharge from the reactor also can be inferred by the presence or absence of fission products with short half-lives, for example, ${ }^{95} \mathrm{Nb}\left(t_{1 / 2}=34.97\right.$ days) and ${ }^{95} \mathrm{zr}$. $\left(t_{1 / 2}=63.98\right.$ days $)$.

This level of verification ensures that fission products are present and that a dumny fuel pin has not been substituted. Without a confinmation of 
fission products, an inspector cannot determine if the fuel pins have been replaced by ${ }^{60}$ co-activated pins. Therefore, this is a higher level of verification than other previously described techniques.

The presence of actinides can be inferred by the measurement of the neutron signature of the fuel assembly. Neutrons emitted from an irradiated fuel assembly can originate primarily from three sources:

(1) spontaneous fission of actinide isotopes;

(2) interaction of alpha particles from radioactive decay of transuranic isotopes $\left({ }^{238} \mathrm{Pu},{ }^{241} \mathrm{Am},{ }^{242} \mathrm{~cm}\right.$, and others) with ${ }^{18} 0$ in the oxide fuel; and

(3) induced fission in the fissile material from the first two sources. Over short cooling times (less than a few weeks), photoneutron production from the $150 \mathrm{ppm}$ of ${ }^{2} \mathrm{H}$ in natural water can be significant. Principal gamma rays with energies greater than the $2.2 \mathrm{MeV}$ photoneutron reaction threshold come from the decay of ${ }^{140} \mathrm{La}\left(t_{1 / 2}=40.2 \mathrm{~h}\right)$, which is in equilibrium with its parent isotope ${ }^{140} \mathrm{Ba}\left(t_{1 / 2}=12.8\right.$ days $)$. Another minor source of photoneutrons comes from a small number of high-energy gamma rays from ${ }^{106} 6_{R h}\left(t_{1 / 2}=29.8 \mathrm{~s}\right)$, which is the daughter of ${ }^{106} \mathrm{Ru}\left(t_{1 / 2}=366.4\right.$ days). In this report, we assume that the number of neutrons originating from the photoneutron reactions is insignificant and that source neutrons originate primarily from the isotopes listed in Table II by the $(\alpha, n)$ reaction and spontaneous fission.

The curium isutopes are the dominant sources of neutrons within irradiated fuel assemblies with exposures above $10 \mathrm{Gma} / \mathrm{tU}$ (Ref. 14). As shown in Table YI, most of the neutrons from ${ }^{242} \mathrm{~cm}$ and ${ }^{244} \mathrm{~cm}$ come from spontaneous fission, with $\bar{v}$ being $2.51 \pm 0.06$ for ${ }^{242} \mathrm{~cm}$ and $2.681 \pm 0.011$ for ${ }^{244} \mathrm{~cm}$ (Ref. 14). The plutonium isotopes can contribute a significant proportion to the total neutron source for fuel assemblies with relatively low exposures $(<10$. Ga/tu) or for fuel assemblies with extremely long cooling times (>100 yr). The uranium isotopes are significant neutron sources only in unirradiated fuel material: that do not contain transuranic iaotopes.

The principal source of neutrons in a fuel assembly changes as the irradiation exposure increases. Figure 1 shows the calculated neutron production per cubic centimeter of fuel material for the five largest contributors to the total neutron signal. For the first case, an exposure of $10.9 \mathrm{GNd} / \mathrm{tu},{ }^{242} \mathrm{Cm}$ is the primary source at the time. of discharge, with $244 \mathrm{~cm}$ becouing the doninant source after 2 years of cooling. For higher exposures $(>20 \mathrm{Gid} / \mathrm{t}$ ) the $244 \mathrm{Cm}$ 
TABLE II

PRINCIPAT SOURCES OF NEUTRONS IN IRRADIATED UO 2 MATERIAIS

\begin{tabular}{|c|c|c|c|c|}
\hline Isotope & $\begin{array}{l}\text { Half-Life } \\
(y r) \\
\end{array}$ & $\begin{array}{l}(\alpha, n)^{a} \\
\text { Reaction }\end{array}$ & $\begin{array}{l}\text { Spontaneous } \\
\text { Fission } \\
\end{array}$ & Totala \\
\hline 23 & $7.04 \times 10^{8}$ & $7.11 \times 10^{-4}$ & $2.99 \times 10^{-4}$ & $1.01 \times 10^{-3}$ \\
\hline & $4.47 \times 10^{9}$ & $8.26 \times 10^{-5}$ & $1.36 \times 10^{-2}$ & $1.37 \times 10^{-2}$ \\
\hline & $8.78 \times 10^{1}$ & $1.34 \times 10^{4}$ & $2.59 \times 10^{3}$ & $1.60 \times 10^{4}$ \\
\hline & $2.41 \times 10^{4}$ & $3.81 \times 10^{1}$ & $2.18 \times 10^{-2}$ & $3.82 \times 10^{1}$ \\
\hline & $6.55 \times 10^{3}$ & $1.41 \times 10^{2}$ & $9.09 \times 10^{2}$ & $1.05 \times 10^{3}$ \\
\hline & $1.47 \times 10^{1}$ & $1.27 \times 10^{0}$ & & $1.27 \times 10^{1}$ \\
\hline & $3.76 \times 10^{5}$ & $2.05 \times 10^{0}$ & $1.72 \times 10^{3}$ & $1.71 \times 10^{3}$ \\
\hline & $4.32 \times 10^{2}$ & $2.69 \times 10^{3}$ & $1.18 \times 10^{0}$ & $2.69 \times 10^{3}$ \\
\hline${ }^{242} \mathrm{C}$ & $4.46 \times 10^{-1}$ & $3.76 \times 10^{6}$ & $2.10 \times 10^{7}$ & $2.48 \times 10^{7}$ \\
\hline${ }^{244} \mathrm{~cm}$ & $1.81 \times 10^{1}$ & $7.73 \times 10^{4}$ & $1.08 \times 10^{7}$ & $1.09 \times 10^{7}$ \\
\hline
\end{tabular}

$a_{\text {Neutrons per gram per second. }}$

bInsignificant level.

is the dominant source of neutrons and is directly related to the fuel assembly exposure. 14

D. Relative Concentrations of Fission Products and Actinides

1. Fission Products. For gamma-ray measurement techniques that are routinely applied to spent-fuel assemblies, HRGS is the most widely investigated and accepted technique. ${ }^{7}$ The exposures of spent-fuel assenblies are generally correlated with ${ }^{137} \mathrm{Cs},{ }^{134} \mathrm{Cs} /{ }^{137} \mathrm{Cs}$, and ${ }^{154} \mathrm{Eu} /{ }^{137} \mathrm{Cs}$ in the HRGS wathods. The ${ }^{137} \mathrm{Cs}$ isotope has a long half-life, similar fission yields for ${ }^{235} \mathrm{U}$ and ${ }^{239} \mathrm{Pu}$, and an easily resolvable gammarray spectrum. Changes in the scanning geonatry or the distribution of the source can affect the measured results. Using an isotopic ratio 1 ike ${ }^{134} \mathrm{Cs} /{ }^{137} \mathrm{Cs}$ or ${ }^{154} \mathrm{Eu} /{ }^{137} \mathrm{Cs}$, we can correct changes in the source attenuation with an internal relative efficiency calibration. 7,15 The initial ${ }^{235} \mathrm{U}$ enrichment can influence significantly the correlation of these two ratios with exposure. Therefore, some information about the Initial enrichment is necessary for the correct interpretation of the results. 

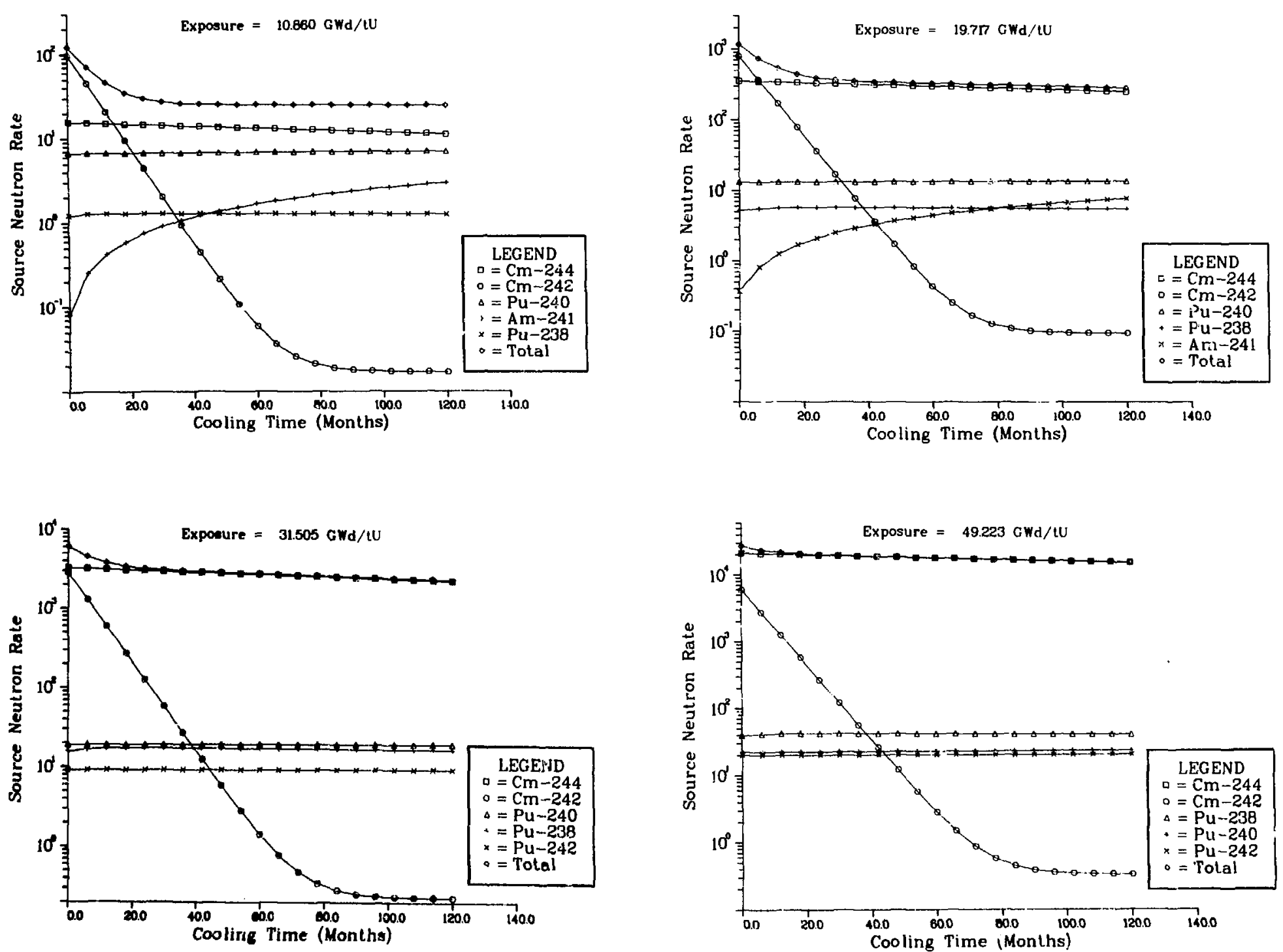

F rig. 1. Relutive neutron source rates for each of the five largest contributors to the total neutron rate. 
Some experimenters have attempted to establish correlations between the number of days since discharge and various isotopic concentrations and ratios.16,17 Knowledge of the cooling time is of particular importance for the ${ }^{134} \mathrm{Cs} /{ }^{1.37} \mathrm{Cs}$ ratio because of the relatively short half-1ife of ${ }^{134} \mathrm{Cs} / t_{1 / 2}=$ $2.062 \mathrm{yr}$ ). Cooling time is also important in the interpretation of the passive neutron measurements of spent-fuel assemblies. The primary sources of neutrons in irradiated fuel materials are ${ }^{242} \mathrm{~cm}\left(t_{1 / 2}=163\right.$ days $)$ and ${ }^{244} \mathrm{Cm}\left(t_{1 / 2}=\right.$ $18.11 \mathrm{yr}$ ): if the cooling time is greater than 3 years, the source is only related to the build-up of ${ }^{244} \mathrm{Cm}$ for exposures above $10 \mathrm{Gwa} / \mathrm{tu}$.

Gamma-ray measurements should be interpreted cautiously. How much of the volume of the fuel assembly do they represent? For a PWR fuel assenbly, only the outer three or four rows of fuel pins contribute to the ${ }^{134} \mathrm{Cs}$ and ${ }^{137} \mathrm{cs}$ signals. Table III gives the percentage of the total gamma-ray signal derived from each row of fuel pins. These values were calculated using a Monte carlo technique to track each photon originating in the specific fuel pin positions.

For verification, HRGS is currently the most widely accepted technique; howe rer, the inspector must consider the source self-attenuation, as shown in Table III. This table illustrates the advantage of using a high-energy rather than a lower energy gamma ray to obtain a representative signature of the cross section of a fuel assembly. The measurement technique has been applied to BMR fuel assemblies and compared with destructive measurements with reasonabiy good success. 7

TABLE III

PERCENTAGE OF GAMM RAYS FROM EACH ROW BASED ON THE TOTAL VALUB

\begin{tabular}{|c|c|c|c|c|c|}
\hline \multirow[b]{2}{*}{ Isotope } & \multirow[b]{2}{*}{$\begin{array}{l}\text { Energy } \\
\text { (kev) }\end{array}$} & \multicolumn{4}{|c|}{ Row Number } \\
\hline & & $\begin{array}{c}1 \\
(3) \\
\end{array}$ & $\begin{array}{c}2 \\
(3) \\
\end{array}$ & $\begin{array}{c}2 \\
(3) \\
\end{array}$ & 4 \\
\hline $134 \mathrm{C}$ & 605 & 67.6 & 20.6 & 8.6 & 3.2 \\
\hline & 796 & 54.0 & 22.4 & 11.9 & 5.2 \\
\hline${ }^{137} \mathrm{C}$ & 662 & 61.5 & 20.7 & 9.5 & 3.5 \\
\hline${ }^{154} \mathrm{Eu}$ & 1274 & 40.2 & 22.4 & 15.2 & 7.7 \\
\hline${ }^{144} \mathrm{Pr}$ & 2186 & 32.8 & 20.7 & 15.9 & 9.1 \\
\hline
\end{tabular}


2. Actinide concentrations. The neutron source rate is related to the exposure of spent-fuel assemblies with exposures above $10 \mathrm{Gwd} t \mathrm{tU}$ by a power functional relationship (Fig. 2). This relationship has been confirmed by calculational and experimental measurements. ${ }^{14}$ The penetrability of neutrons is much greater than that of gamma rays; therefore, neutron measurement more accurately samples the entire cross section of the fuel assembly.

Instrumentation for measuring the neutron signature of fuel assemblies includes a neutron detector (probsbly a ${ }^{235} \mathrm{U}$ fission chamber), the power supply, an amplifier, and a scaler/timer. Relatively simple and easily operateci, these instruments measure a single midpoint in less than $5 \mathrm{~min}$ per fuel assembly.

E. Direct Neasurement of Special Nuclear Material

The neutron and gamma-ray signatures of uranium and plutonium isotopes cannot be measured directly because of interference from other actinides and fission products. As shown in Fig. 1, most of the neutrons came from the curium isotopes, with only a small percentage of neutrons originating in ${ }^{240} \mathrm{Pu}$ and ${ }^{233} \mathrm{Pu}$.

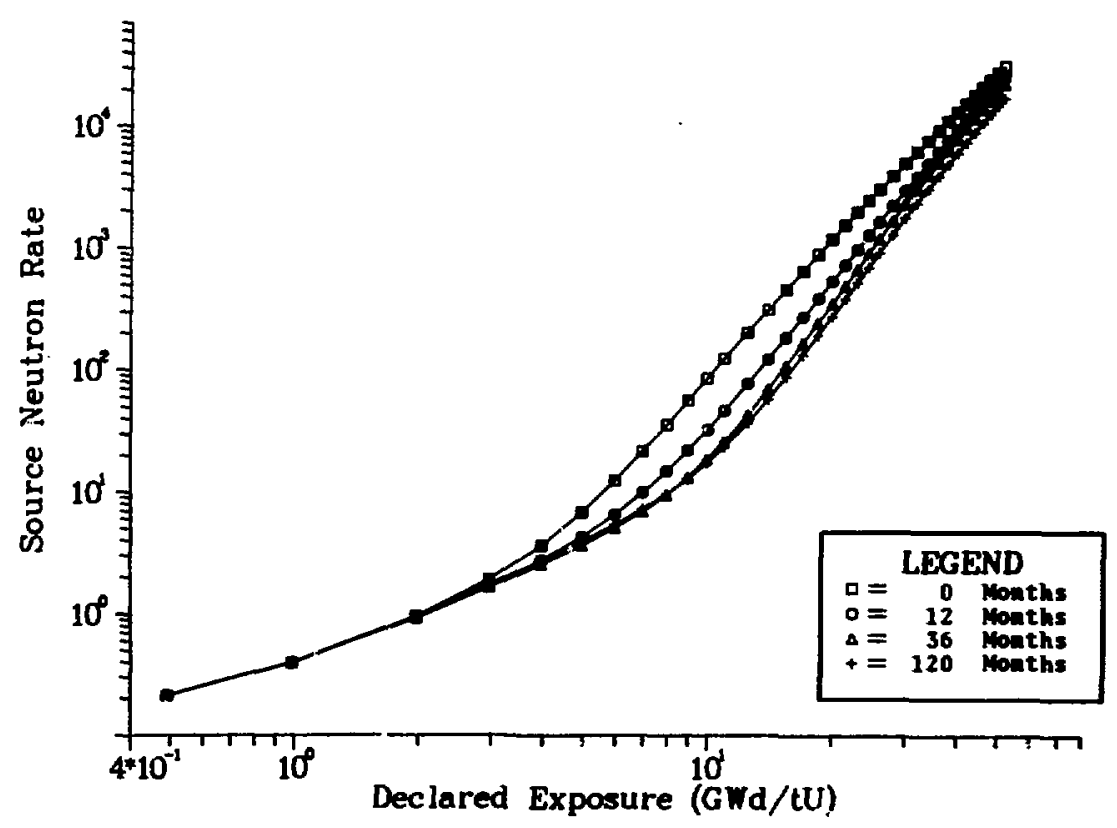

Fig. 2. Neutron source rate as a furction of exponure for four cooling times. 
Uranium-235 and ${ }^{239} \mathrm{Pu}$ gamma-ray lines cannot be measured using HRGS because of the large numbers of fission product gamma rays. For irradiated reactor fuel with $30 \mathrm{GWd} / \mathrm{tU}$ exposure, the prominent $414-\mathrm{keV}$ line of ${ }^{239} \mathrm{Pu}$ has an intensity of only 1392 gamma rays $/ \mathrm{cm}^{3} / \mathrm{s}$, whereas the fission product ${ }^{137} \mathrm{cs}$ emits $4.38 \times 10^{10}$ gamna rays $/ \mathrm{cm}^{3} / \mathrm{s}$. For each $239 \mathrm{Pu} 414-\mathrm{keV}$ gama ray emi.tted, more than 30000000 gaima rays are emitted from the single fission product ${ }^{137} \mathrm{Cs}$. Any gamma ray from the fissile isotopes is completely overwhelmed by the fission product gamma rays and their associated compton backgrounds. Therefore, the concentration of fissile isotopes in spent fuel must be measured indirectly by relating the build-up of specific fission products to the depletion of the ${ }^{235} \mathrm{U}$ and the build-up of plutonium.

III. EXPERTMENTAI MEASUREMENTS

Based on the akove discussions of the measurement techniques available for each level of verification, we selected a combination of gama-ray and neutron measurements as the most cost-effective and practical considering the quality of information collected and time required for the measurements. By determining the gross gama-ray signatures of the fuel assemblies, an inspector can obtain a qualitative measurement of the consistency of the operator-declared cooling times. Figure 3 shows the relationship between the calculated response from PWR fuel assemblies divided by the exposure as a function of cooling time. The curve approximates a power function decay curve with the power factor being approximately equal to -1 with respect to cooling time. Having collected a set of measurements of the gross gamma-ray loses, an inspector can plot the data on a similar curve to determine the internal consistency of the measured data set.

The second measurement, performed simultaneously with the gama-ray measurements, is a passive neutron measurement that determines the relative exposure of the set of fuel assemblies through the power functional relationship described in Sec. II. Using these two measurenents, an inspector can obtain information rapidly about both the relative cooling time and the exposure of each fuel assembly, without interfering with the operator unnecessarily.

To determine the applicability of these two nondestructive techniques we uged two experinental detector configurations. A aquare-ring detector capable 


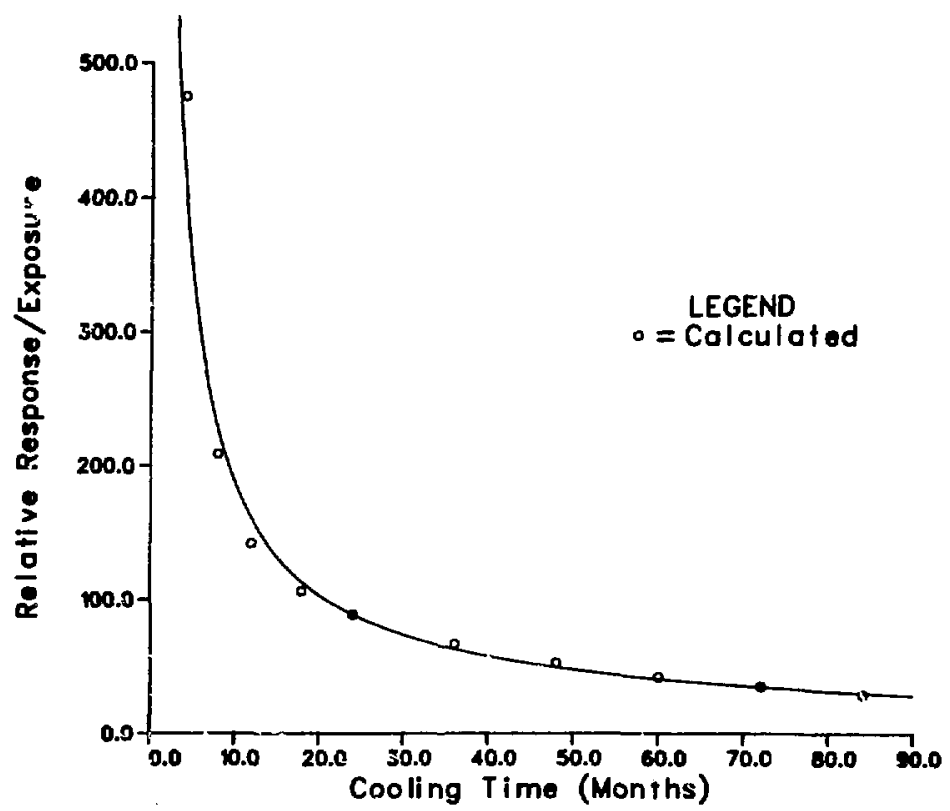

Fig. 3. Calculated response of dose divided by exposure as a function of cooling time for PWR fuel assemblies.

of measuring the gross gamma-ray and neutron signatures for each of the four sides of the irradiated fuel assemblies was fabricated. Figure 4 shows the components of the detector assembly. Four ${ }^{235} \mathrm{U}$ fission chambers $\left(130 \mathrm{mg}{ }^{235} \mathrm{U}\right.$ each) and four ionization chambers were mounted on the detector support ring

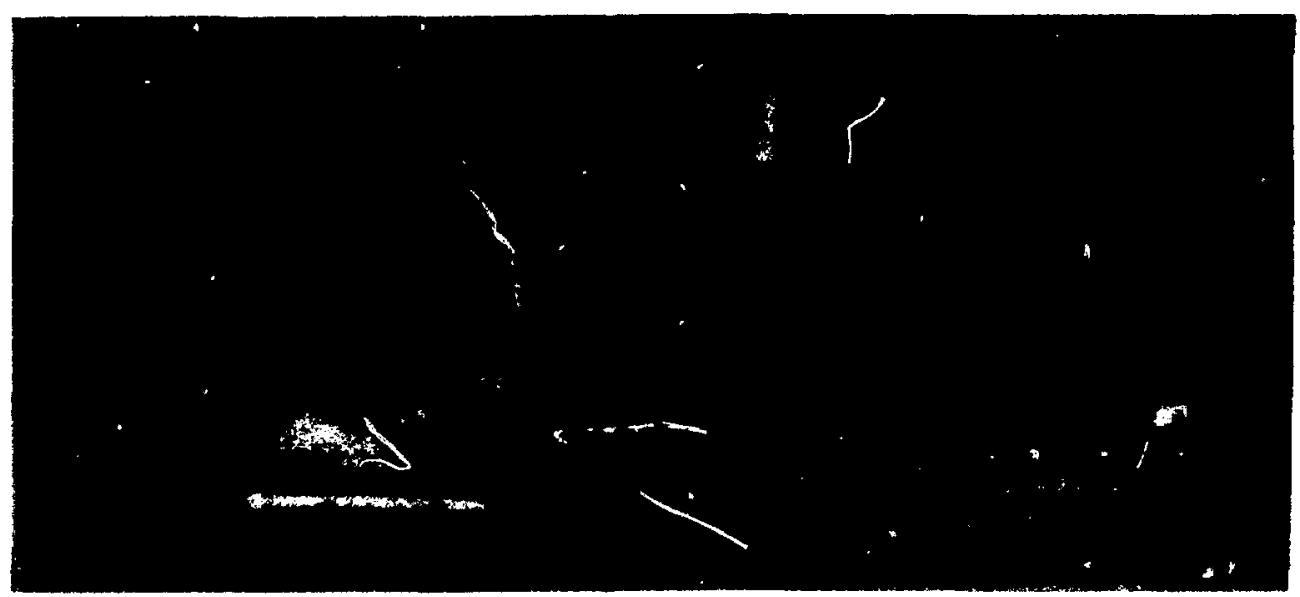

Fig. 4. Components of the square-ring detector. 
and inserted into an aluminum watertight assembly. The inside dimension of the detector was $25.6 \mathrm{~cm}$ to allow easy insurtion of $\mathrm{PWR}$ fuel assemblies with $20-\mathrm{cm}$ widths (Fig. 5). The detector was attached to a fixture that was fitted to the fuel storage baskets used at the G. E. Morris operation SpentFuel Storage Facility at Morris, Illinois. The detector could be placed on top of the storage racks at reactor storage basins. 14,16

The second measurement system consisted of a $\mathrm{V}$-shaped positioning mechanism attached to a tube containing various gamiria-ray and neutron detectors. The device was suspended from the wall in the receiving pool (Fig. 6). The fuel assembly was moved $t:$ the $v$-shaped

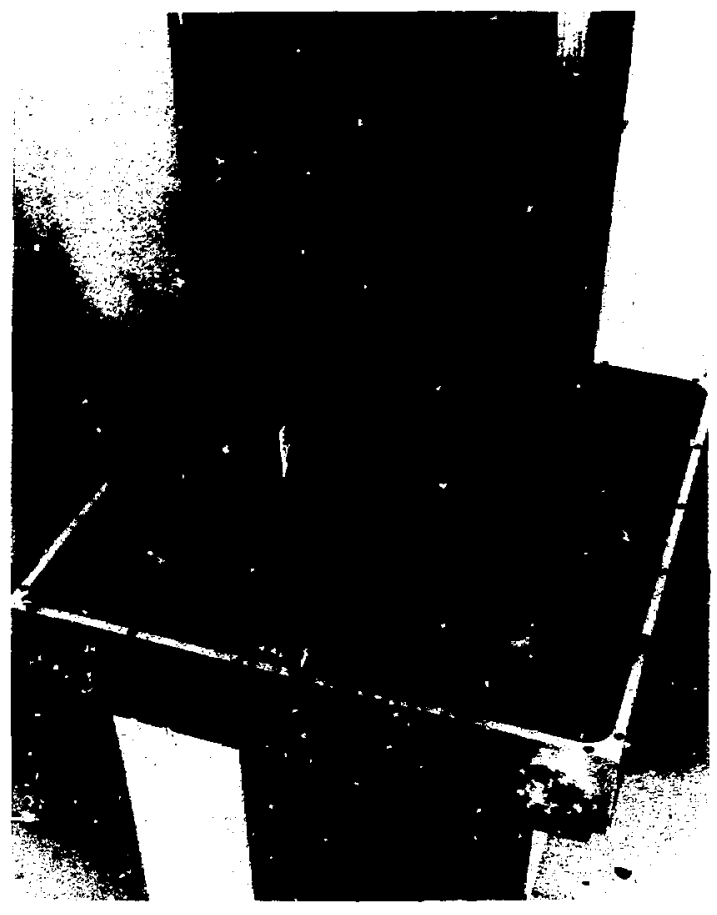

Fig. 5. Square-ring detector and an irradiated $P$ WR fuel assembly. positioning fixture, which automatically positioned the assembly correctly (Fig. 7) in less than a minute of the operator's time. The detector pipe was located at the corner of the fuel assembly to ensure a reproducible measurement geometry. The detector package consisted of

- an ion chamber to measure gross-gamma dose,

- a ${ }^{235} \mathrm{U}$ fission chamber ( $130 \mathrm{mg}{ }^{235} \mathrm{U}$ ) to measure the neutron emission rate, and

- a $\operatorname{Be}(\gamma, n)$ detector to record the high-energy ( $>1.66 \mathrm{MeV})$ ganma signature. 16

Figure 8 shows a PWR fuel assembly in the measurement position.

The gamma-ray and neutron signals were recorded using two sets of electronics. The ion and neutron (ION-I) electronics unit records one gama-ray and one neutron readout. 18 This battery-operated unit was developed for the IAEA inspectors. A microprocessor unit can read each of the four ion chanbers and four fission chambers individually and simultaneously. The microprocessor system provides discrete information about the individual sides of the fuel 


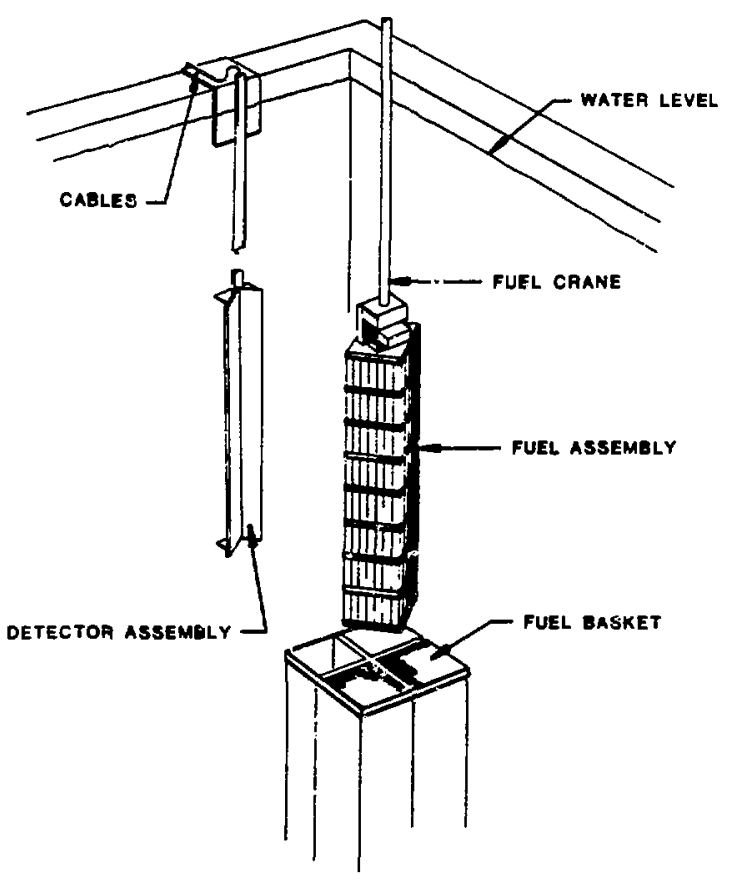

Fig. 6. Locating assembly with detector tube.

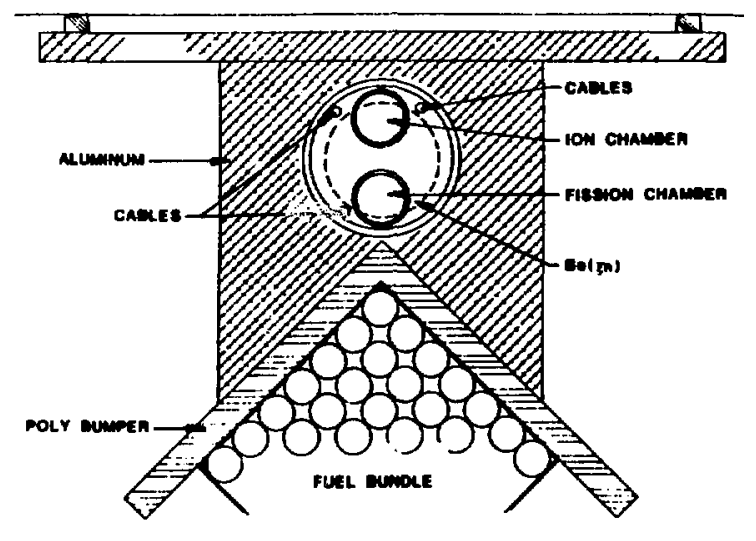

Fig. 7. Relative position of fuel assembly and detector tube and detector package used in $\mathrm{v}$ detector.

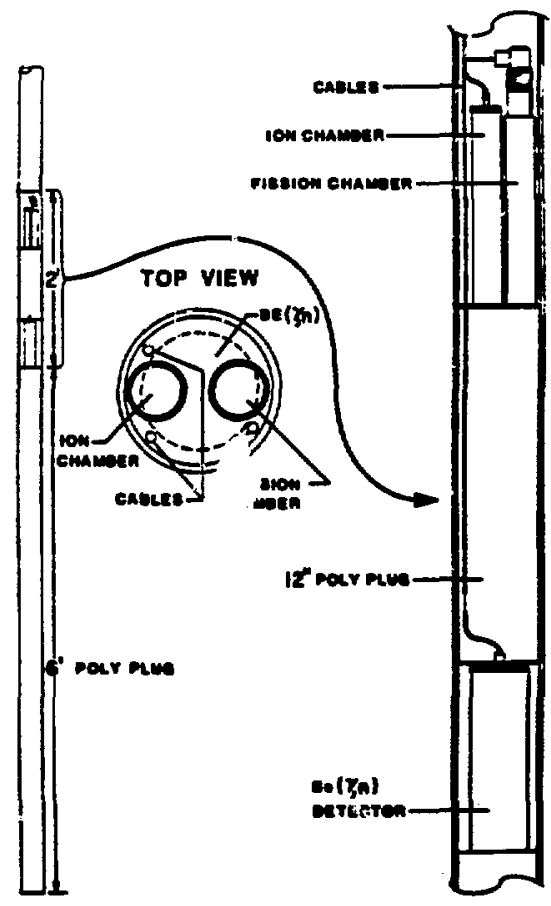


assembly, whereas the ION-I results are integral values for the side measurements.

\section{NEUTRON MEASUREMENTS}

The square-ring detector described in Sac. III was evaluated at Ios Alamos before being shipped to the G. E. Morris Operatior. Spent-Fuel Storage Facility for testing and evaluation with irradiated fue? assemblies. Measurements of the neutron detection sensitivity used a ${ }^{252}$ cf source underwater with and without the presence of an unirradiated fuel assembly. At the Morris Facility a variety of measurements demonstrated the applicability of this particular detector arrangement

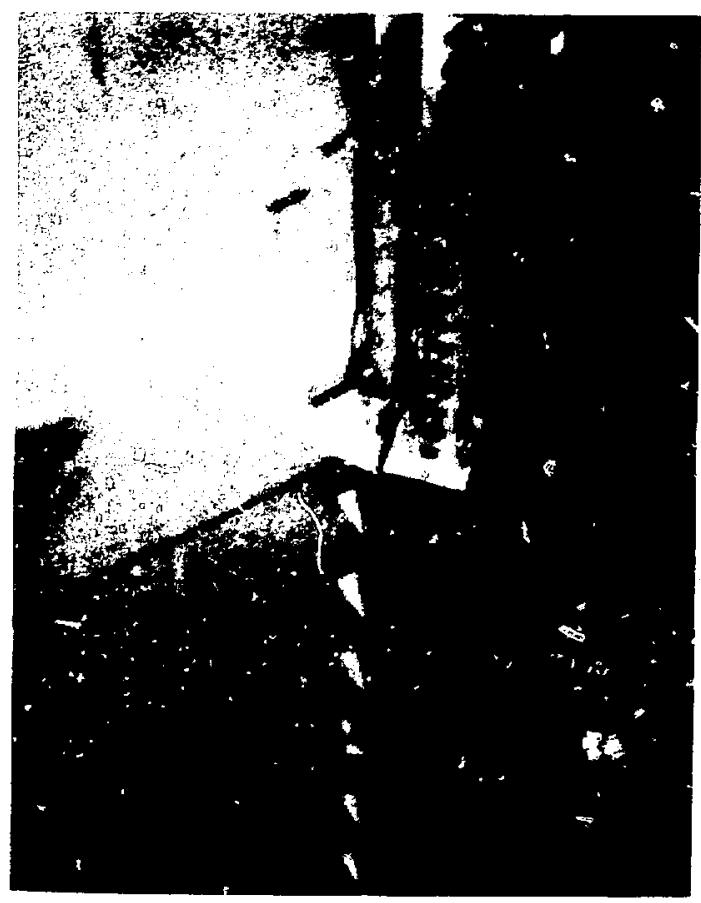

Fig. 8. PWR fuel assembly located in positioning assembly for measurement. for the rapid and precise verification of irradiated fuel assemblies. Thes. measurements included

- reproducibility measurements for estimation of precision,

- measurement of each side of an individual fuel assemoly to determine the variability of source strengths,

- comparison with measurements using the two detector systems, and

- correlation between the measured neutron emission rates and the operator-declared values of exposure.

\section{A. Evaluation of the Square-Ring Detector Using Calibrated Sources}

For test purposes, the square-ring detector was placed in a cylinder (61.0-cm diam) filled with water. A minimum of $30 \mathrm{~cm}$ of water was above and below the detector. A polyethylene sheet was fabricated to hold a ${ }^{252} \mathrm{CF}$ source at specified positions inside the detector. The positions were at 3.0-cm intervals, with nine positions available across the 26.04-cm inside distance. The ${ }^{252}$ cf-source strength was $3.75 \pm 0.01 \times 10^{5} \mathrm{n} / \mathrm{s}$. Figure 9 shows 


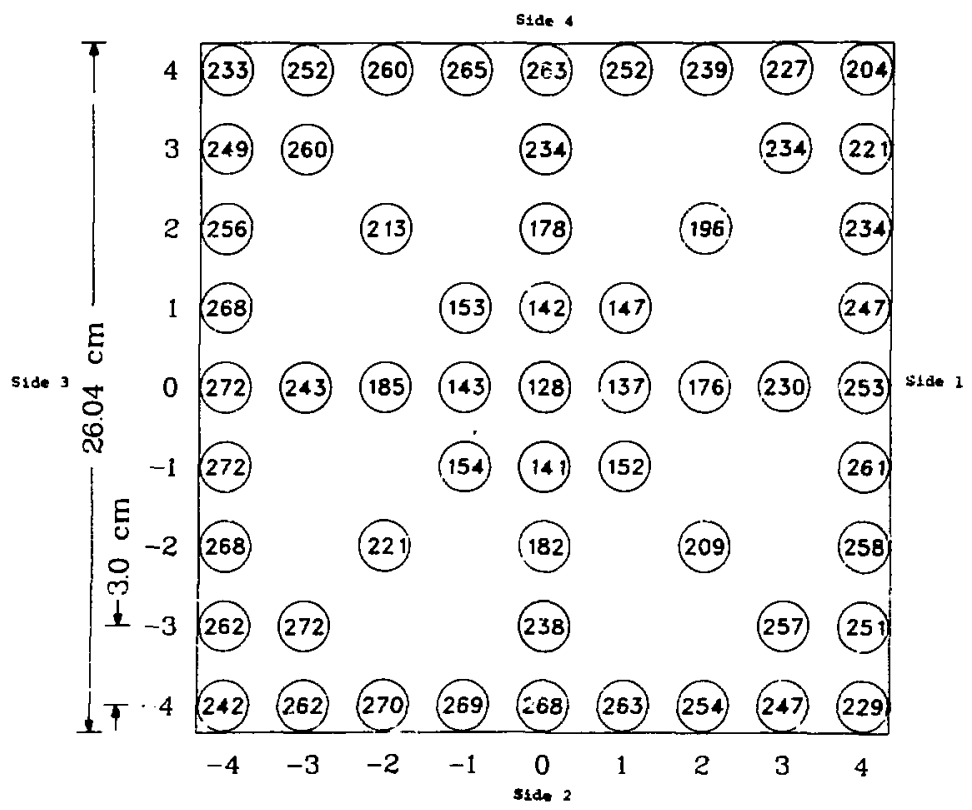

(a)

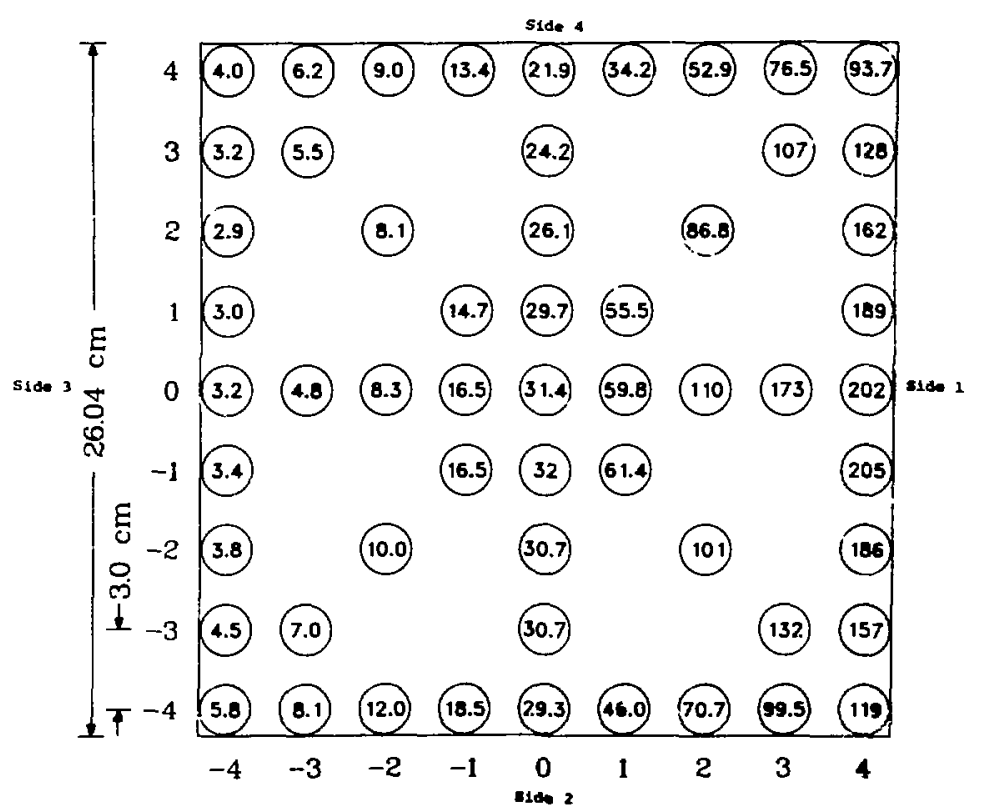

(b)

Fig. 9. Responses of a calibrated source at apecified locations inside the square-ring detector for (a) all four detectora and (b) side 1 detector. 
the measured results for one of the four detectors as well as the sumation of the four detectors for the source in each of 57 positions. The threshold for each fission chamber was set at the minimum between the alpha pulse and the fission fragment signals. The numbers given at each location in Fig. 9 are the counts per second measured from the ${ }^{252}$ cf source. The counting precision for the data s'mming the four detectors was approximately $0.5 \%$.

There appears to be a slight skew to the two-dinensional response, with the lower left-hand corner (between sides 2 and 3 ) being about 108 higher than the top right-hand corner (between sides 4 and 1 ). The fission chambers used in this detector had an active length of $12.5 \mathrm{~cm}$ and relative efficiencies within 0.68 . The effect of any detector skew is significantly reduced when the data for each detector are sunemed over all 57 source positions. When a fuel assembly is present, its effect upon source multiplication further reduces the effect of the skew.

Figure 10 shows the responses for each of the four detectors to the underwater movement of the source from the detector. The responses for each of the detectors were essentially identical. The source was noved from the detector along a line perpendicular to the axis of each detector.

These measurements showed the sensitivity of the square-ring detector to a calibrated ${ }^{252} \mathrm{Cf}$ source placed at specified $x-y$ locations. The next step in the characterization of the detector was using a fuel assembly to introduce source multiplication and absorption.

B. Evaluation of the Square-Ring Detector Using a Simulated Fuel Assembly

An unirradiated $15 \times 15$ fuel assembly loaded with $3.23^{235} \mathrm{U}$-enriched fuel pins was placed in the water container. The square-ring detector was positioned to center the fuel assembly inside the detector. The fuel assembly contains 204 fuel pin positions and 21 guide-tube positions (Fig. 11). The ${ }^{252}$ Cf source was placed into each of the 21 guide-tube positions at the

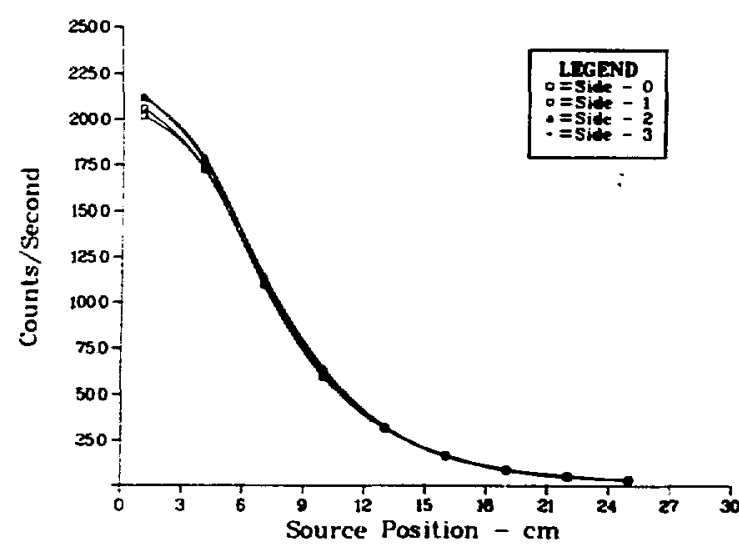

Fig. 10. Heasured response of a source noved perpendicujar to the axis of the detector. 
vertical height corresponding to the midplane of the detector. Neutron emission rates were measured at each of the four fission chambers and were surmed for the total response.

Figure 12 shows the results for the fuel assembly positioned at these different locations within the squarering detector. The maximum detection efficiency was with the fuel assembly at the center of the square-ring detector; the minimum, with the fuel assembly in the corner. Maximum variability between the two sample locations was 278.

Three factors influence the meassource measurenents of a $15 \times 15$ PWR fuel assembly.

Fig. 11. Cross section of fuel assem-

bly used in the sinulated

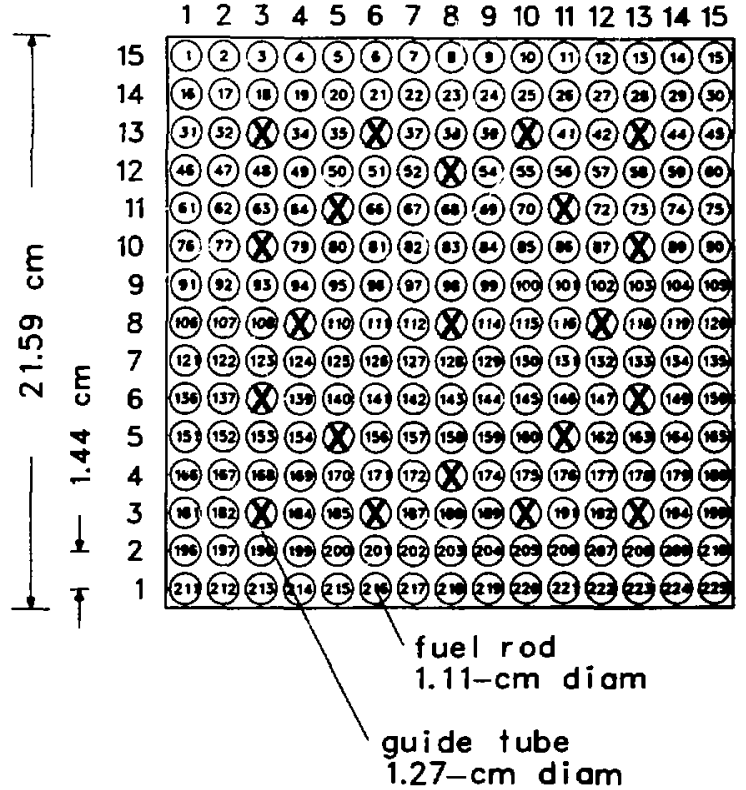
assembly geometries described in Fig. 12:

(1) the distance between the detector and the fuel assembly ( $1 / x$ effect),

(2) neutron absorption in the fuel assembly, and

(3) alteration of the thermalizing layer of water between the detector and fuel assembly.

As the fuel assembly is positioned against the side of the detector [(Fig. $(12 b)]$, the count rate should rise as a result of the $1 / x$ effect; however, this effect is more than compensated for by factors (2) and (3). The fission chanbers in the detector do not have any moderating material around them. $\boldsymbol{A}$ lower detection efficiency therefore results from the lack of any thermalizing moderator when the water is removed between the detactor and the fuel asscably. The fuel assembly, which absorbs any neutron scattered back, reduces the counting efficiency by approximately 15 for the $12(\mathrm{~b})$ case and 27 for the $12(c)$ case.

The axial sensitivity of the detector was measured by placing the fuel assembly at the center of the square ring and inserting the ${ }^{252}$ ce source into the center guide-tube position. The source was moved vertically, with the noutron enission rate being weasured from 0 to $20 \mathrm{~cm}$ above the nidplane of the detector. Figure 13 shows the measured results as a function of axial position. 
the measured results for one of the four detectors as well as the summation of the four detectors for the source in each of 57 positions. The threshold for each fission chamber was set at the minimum between the alpha pulse and the fission fragment signals. The numbers given at each location in Fig. 9 are the counts per second measured from the ${ }^{252}$ cf source. The counting precision for the data summing the four detectors was approximately $0.5 \%$.

There appears to be a slight skew to the two-dimensional response, with the lower left-hand corner (between sides 2 and 3 ) being about 108 higher than the top right-hand corner (between sides 4 and 1 ). The fission chambers used in this detector had an active length of $12.5 \mathrm{~cm}$ and relative efficiencies within 0.68 . The effect of any detector skew is significantly reduced when the data for each detector are summed over all 57 source positions. Then a fuel assembly is present, its effect upon source multiplication further reduces the effect of the skew.

Figure 10 shows the responses for each of the four detectors to the underwater movement of the source from the detector. The responses for each of the detectors were essentially identical. The source was moved from the detector along a line perpendicular to the axis of each detector.

These measurements showed the sensitivity of the square-ring detector to a calibrated ${ }^{252}$ cf source placed at specified $x-y$ locations. The next step in the characterization of the detector was using a fuel assembly to introduce source multiplication and absorption.

B. Evaluation of the Square-Ring Detector Using a Simulated Fuel Assembly

An unirradiated $15 \times 15$ fuel assembly loaded with $3.28{ }^{235}$ U-enriched fuel pins was placed in the water container. The square-ring detector was positioned to center the fuel assembly inside the detector. The fuel assembly contains 204 fuel pin positions and 21 guide-tube positions (Fig. 11). The 252 cf source was placed into each of the 21 guide-tube positions at the

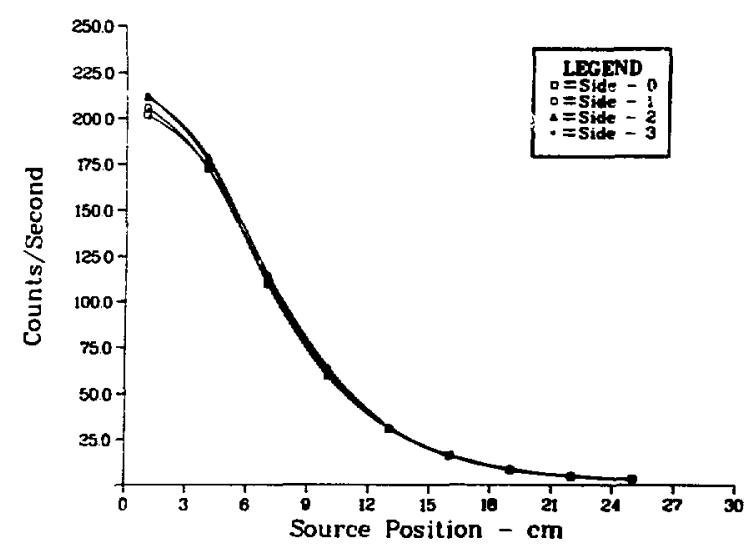

Fig. 10. Keasured response of a source noved perpenaicular to the axis of the detector. 
vertical height corresponding to the midplane of the detector. Neutron emission rates were measured at each of the four fission chambers and were summed for the total response.

Figure 12 shows the results for the fuel assembly positioned at these different locations within the squarering detector. The maximum detection efficiency was with the fuel assembly at the center of the square-ring detector; the minimum, with the fuel assembly in the corner. Maximum variability between the two sample locations was 278 .

Three factors influence the measured variability in the detector-fuel assembly geometries described in

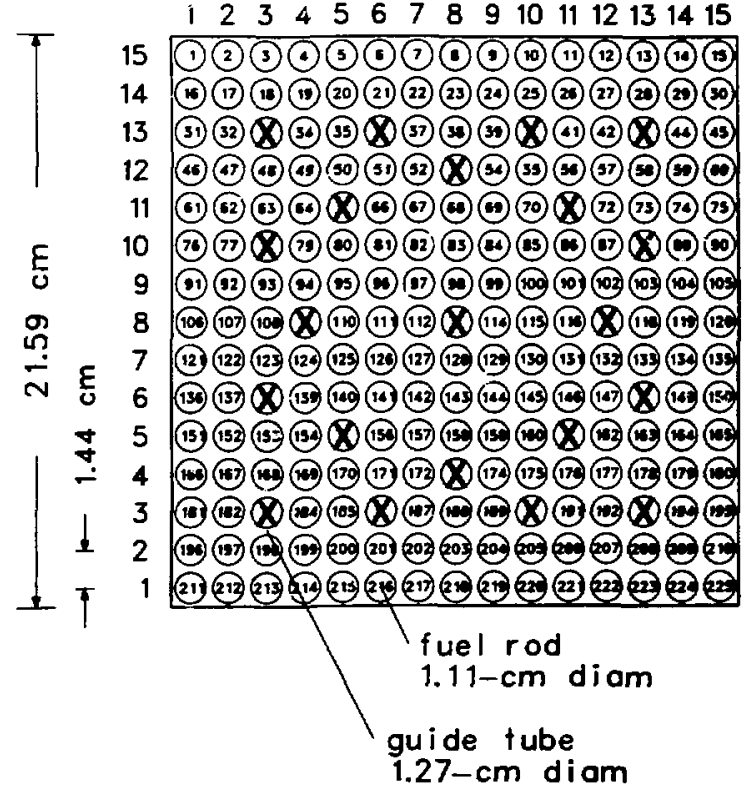

Fig. 11. Cross section of fuel assenbly used in the sinulated source measurements of a $15 \times 15$ PWR fuel assembly.

Fig. 12:

(1) the distance between the detector and the fuel assembly ( $1 / r$ effect),

(2) neution absorption in the fuel assembly, and

(3) alteration of the thermalizing layer of water between the detector and fuel assembly.

As the fuel assembly is positioned ayainst the side of the detector I(Fig. (12b)], the count rate should rise as a result of the $1 / x$ effect; however, this effect is nore than compensated for by factors (2) and (3). The fission chanbers in the detector do not have any moderating material around tiven. $\mathrm{A}$ lower detection efficiency therefore results from the lack of any thermalizing moderator when the water is renoved between the detector and the fuel assembly. The fuel asserably, which absorbs any neutron scattered back, reducen the counting efficiency by approximately 15t for the $12(\mathrm{~b})$ case and 27 for the $12(\mathrm{c})$ case.

The axial sensitivity of the detector was masured by placing the fuel assembly at the center of the square ring and Inserting the ${ }^{252}$ ce source into the center guide-tube position. The source was moved vertically, with the neutron emission rate being measured from 0 to $20 \mathrm{~cm}$ above the midplane of the detector. Figure 13 shows the measured results as a function of axial poaition. 

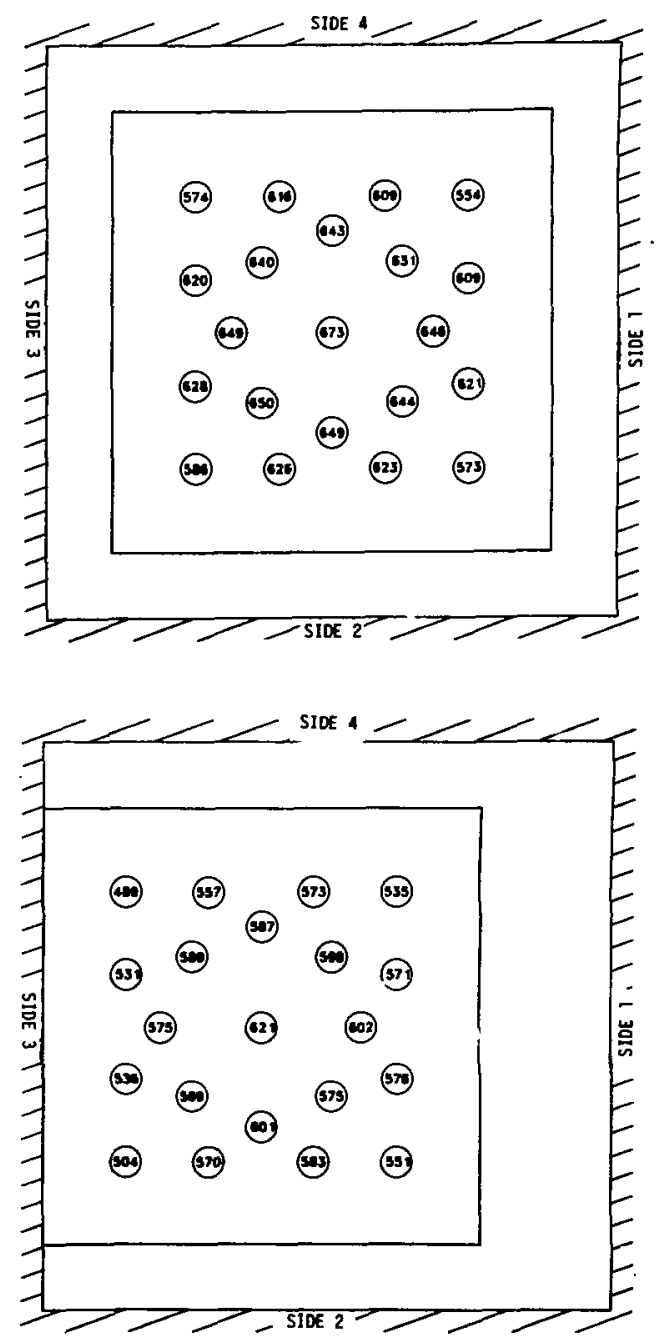

Fig. 12. Measured neutron rates (count/s) for the $252 \mathrm{Cf}$ in the 21 guidetube positions for three different measurement geonetries.

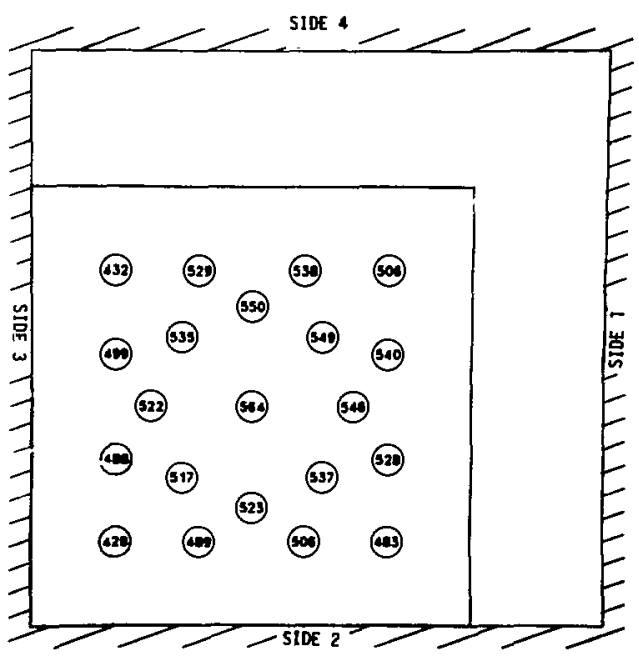




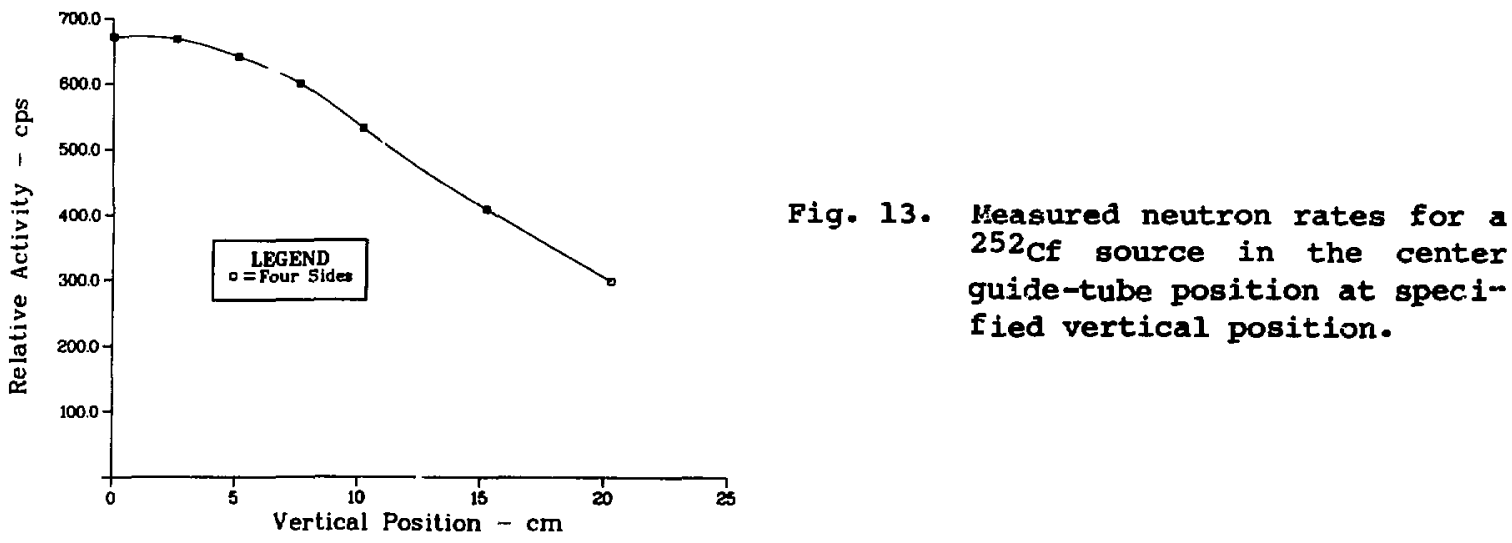

At $5.0 \mathrm{~cm}$ above the detector's midplane the detector's response is 95.58 of the source at the midplane. A 748 contribution still exists at the 20-cm vertical position.

These measurement.s show that the position sensitivity of the detector is reduced by the effects of neutron multiplication and absorption upon neutron sources. The square ring measured an extended region of the fuel assembly, about $40 \mathrm{~cm}$ long.

c. Measurement of Irradiated PWR Fuel Assemblies

A series of nondestructive neutron and gamma-ray measurements was performed on a set of 14 PWR fuel assemblies with exposures ranging from 18.4 to $40.6 \mathrm{Gma} / \mathrm{tU}$. These fuel assemblies were irradiated in a $450-\mathrm{kile}$ Westinghousetype PWR. Table IV lists the fuel parameters of each asseably.

Each of the 14 fuel assemblies listed in Table $V$ was placed in the squarering detector that measured each side simultaneously. Both the neutron enission rate and gross ganma-ray dose were recorded using two data acquisition systems, the ION-1 electronics unit and the microprocessor unit.

A second measurement was also performed on each fuel assembly using the v-shaped positioning device ${ }^{14}$ with a fission and ion chamer that moasured the neutron emission rates and gross ganma-ray doses at the corner of the funl assembly. Both of these detectors were placed in a vertical direction as opposed to the horizontal orientation of the fission and ion chanbers in the. square-ring detector. 
TABLE IV

FUEL ASSEMBLY PARAMETERS FOR $14 \times 14$ ARRAY

Euel Assembly

\begin{tabular}{lc}
\hline Width (cm) & 19.7 \\
Length (cm) & 366.0 \\
Upper fuel assembly (kg) & 443.7 \\
& \\
& Fuel Rod \\
\hline Diameter (cm) & 0.93 \\
235 J enrichment (8) & $3.04-3.40$ \\
Cladding & Zircaloy
\end{tabular}

TABLE $v$

FUEL ASSEMBLIES MEASURED AT THE MORRIS SPENT-FUEL STORAGE FACILITY

\begin{tabular}{|c|c|c|c|c|}
\hline $\begin{array}{l}\text { Fuel } \\
\text { Assembly }\end{array}$ & $\begin{array}{l}\text { Discharge } \\
\text { Date }\end{array}$ & $\begin{array}{l}\text { Time Since } \\
\text { Discharge } \\
\text { (Days) } \\
\end{array}$ & $\begin{array}{c}\text { Initial }{ }^{235} \mathrm{U} \\
\text { Enrichuent } \\
\text { (\$) }\end{array}$ & $\begin{array}{l}\text { Declared } \\
\text { Exposure } \\
\text { (Grd/tU) } \\
\end{array}$ \\
\hline$A-72$ & $10 / 16 / 74$ & 2445 & 3.40 & 18.47 \\
\hline$A-54$ & $10 / 16 / 74$ & 2445 & 3.40 & 20.81 \\
\hline$A-74$ & $10 / 16 / 74$ & 2445 & 3.40 & 20.84 \\
\hline$A-73$ & $10 / 16 / 74$ & 2445 & 3.40 & 20.91 \\
\hline$D-31$ & $11 / 16 / 75$ & 2049 & 3.04 & 23.43 \\
\hline$c-32$ & $4 / 6 / 74$ & 2638 & 3.40 & 23.57 \\
\hline$D-26$ & $11 / 16 / 75$ & 2049 & 3.04 & 26.91 \\
\hline$C-51$ & $2 / 26 / 76$ & 1947 & 3.40 & 28.90 \\
\hline$B-52$ & $2 / 26 / 76$ & 1947 & 3.02 & 31.71 \\
\hline$c-52$ & $3 / 4 / 77$ & 1575 & 3.40 & 32.82 \\
\hline$c-70$ & $3 / 4 / 77$ & 1575 & 3.04 & 33.08 \\
\hline$c-72$ & $3 / 4 / 77$ & 1575 & 3.04 & 37.85 \\
\hline$c-56$ & $3 / 4 / 77$ & 1575 & 3.40 & 40.07 \\
\hline$C-64$ & $3 / 4 / 77$ & 1575 & 3.40 & 40.55 \\
\hline
\end{tabular}


The square-ring detector was mounted onto a support bracket (Fig. 14) atop the fuel assembly storage basket used at the facility. Each fuel assembly was first lowered into the square-ring detector with each of the four sides being measured at designated axial positions; then the fuel assembly was moved to the v-detector with each corner being messured separately. This process was repeated for each of the 14 irradiated fuel assemblies.

1. Relationship Between Neutron Emission Rate and Exposure. As was discussed earlier in Sec. II, the neutron source strength varies as a function of exposure by the following equation:

$$
\text { Count Rate }=\alpha * \text { Exposure }^{\beta} \text {, }
$$

where $\alpha$ is a scaling parameter and $\beta$ ranges in value between 2.8 and 4.0 depending upon the fuel being measured. This power function relationship has been verified experimentally for a variety of fuel assemblies. $7,14,16,19$

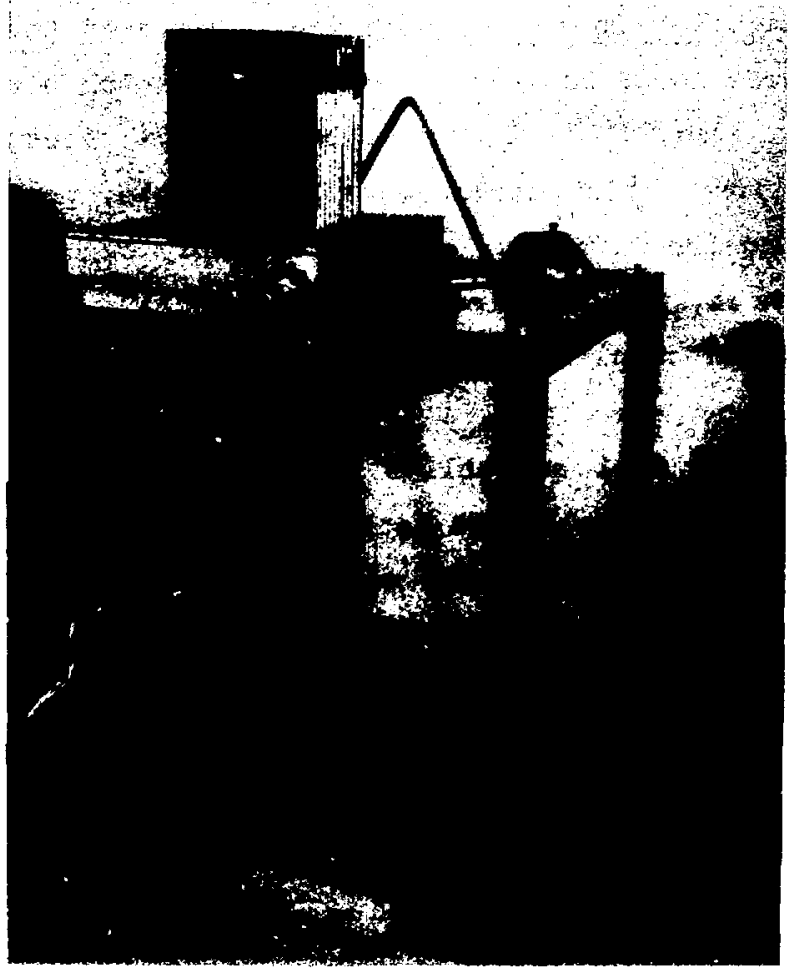

Fig. 14. Square-ring detector. wounted on support bracket, on top of the PWR storage baskets. 
2. Reproducibility heasurements. To demonstrate electronic stability and freedom from positioning problems, a series of repeated measurenents was performed. The fuel assembly $c-32(23.57 \mathrm{GNd} / \mathrm{tU})$ was our standard. It was lowered into the square-ring detector until the midplane of the assembly was positioned at the detector. Measurements of the neutron emission rate and gross gamma-ray dose for each side were recorded. After the fuel assembly was removed from the square ring and movel away from the storage basket, it was returned and repositioner, in the detectors to check reproducibility. This process simulated independent measurements and measured the precision of the entire process (Table VI). For a set of seven measurements, the average deviation was 0.68 for the neutron measurements. The gamma-ray dose measurements agreed even better, with a 0.28 precision. At the beginning of each day's measurements, we remeasured the C-32 fuel assembly. Over a 6-day period the neutron measurements varied an average of 1.58 (Table VII); gamma-ray dose measurements varied by 1.38. Variation in the reproducibility can be divided into two components, uncertainty in the repositioning of the fuel assembly and changes in the counting electronics. (This is discussed in Sec. IV.C.6.) Measurement variation can be related about equally to accurate repositioning of the fuel assembly and the counting statistics. 20

3. Variability in Source Strength at One Axial Location. Measured neutron emission rates can vary by as much as 30 to $40 \%$, depending upon which side or corner of a fuel assembly is measured. 14,20 These asymetries in source strength can be related to specific irradiation histories. For example, positioning near the core periphery during the first cycle of an assembly can create a gradient that persists throughout the lifetine of the assembly. ${ }^{20}$ This asymetry in neutron emission rates can complicate data interpretation by introducing another geometric variable.

Each of the four sides of the 14 fuel assemblies was mosured (Table VIII). The measured neutron activities were corrected back to the time of discharge from the reactor using the $18.1-\mathrm{yr}$ half-life of $244 \mathrm{Cm}$ as the tine factor. As discussed in Sec. II.C, ${ }^{244} \mathrm{~cm}$ is the principal source of neutrons in fuel assemblies with exposures above $10 \mathrm{Gwa} / \mathrm{tJ}$ (Fig. 1 ). The second nont important source of neutrons is ${ }^{242} \mathrm{~cm}$, which has a relatively short half-life $\left(t_{1 / 2}=0.446 \mathrm{y} x\right)$. In this particular set of fuel assemblies, the shortest cooling tine since discharge from the reactor was 1575 diys therefore, only 
TABLE VI

SQUARE-RING REPRODUCIBILITY MEASUREMENTS

Fisgion Chamber ${ }^{a}$

\begin{tabular}{|c|c|c|c|c|c|c|}
\hline \multirow[t]{2}{*}{ Measureaent } & Side 1 & Side 2 & side 3 & Side 4 & \multicolumn{2}{|c|}{ Total } \\
\hline & 5133 & 3690 & 4341 & 6590 & 19 & 754 \\
\hline 1 & 5276 & 3701 & 4442 & 6831 & 20 & 250 \\
\hline & 5004 & 3774 & 4302 & 6878 & 18 & 958 \\
\hline 2 & 5018 & 3635 & 4356 & 6754 & 19 & 763 \\
\hline & 5093 & 3597 & 4375 & 7088 & 20 & 153 \\
\hline 3 & 5080 & 3535 & 4293 & 6885 & 19 & 793 \\
\hline . & 5136 & 3784 & 4338 & 6939 & 20 & 197 \\
\hline 4 & 5180 & 3694 & 4387 & 6901 & 20 & 162 \\
\hline & 5087 & 3680 & 4193 & 7036 & 19 & 996 \\
\hline 5 & 5153 & 3607 & 4289 & 7007 & 20 & 056 \\
\hline & 5075 & 3456 & 4222 & 7043 & 19 & 796 \\
\hline 6 & 5179 & 3693 & 4198 & 6844 & 19 & 914 \\
\hline & 5143 & 3651 & 4307 & 6987 & 20 & 088 \\
\hline 7 & 5021 & 3616 & 4289 & 6830 & 19 & 756 \\
\hline
\end{tabular}

$19974 \pm 112(0.68)$

Ion Chamber

\begin{tabular}{lccccc}
\multicolumn{5}{c}{ Ion Chamber } \\
\cline { 1 - 2 } Side 1 & Side 2 & Side 3 & Side 4 & Total \\
\cline { 5 - 6 } 562 & 395 & 412 & 543 & 1912 \\
561 & 394 & 412 & 544 & 1911 \\
& & & & \\
555 & 368 & 417 & 559 & 1317 \\
555 & 386 & 417 & 559 & 1917 \\
561 & 378 & 411 & 570 & 1920 \\
562 & 378 & 411 & 571 & 1922 \\
571 & 398 & 407 & 541 & 1917 \\
571 & 399 & 407 & 541 & 1918 \\
571 & 382 & 405 & 564 & 1922 \\
572 & 382 & 404 & 565 & 1923 \\
580 & 382 & 399 & 565 & 1926 \\
580 & 382 & 399 & 564 & 1925 \\
568 & 380 & 408 & 567 & 1923 \\
571 & 379 & 405 & 567 & 1922 \\
& & $1919 \pm 4.7$ & $(0.28)$ &
\end{tabular}

We used 60-a counts on fuel aseombly C-32 (23.57 GNd/tU). 


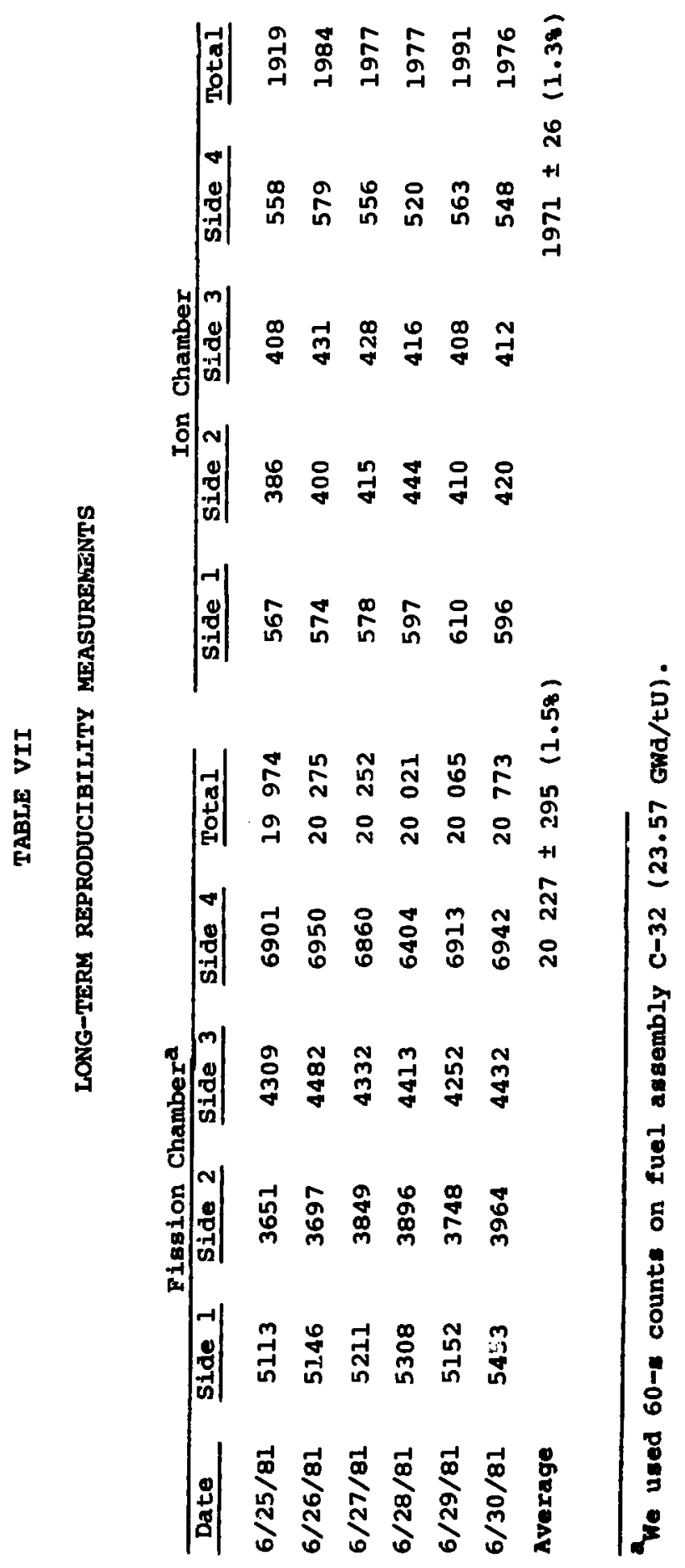


TABLE VIII

MEASURED NEUTRON RESULTS FOR THE GQUARE-RING DETECTOR

\begin{tabular}{|c|c|c|c|c|c|c|}
\hline \multirow{2}{*}{$\begin{array}{l}\text { Fuel } \\
\text { Assembly }\end{array}$} & \multirow{2}{*}{$\begin{array}{l}\text { Declared } \\
\text { Exposure } \\
\text { (GWd/tU) } \\
\end{array}$} & \multicolumn{5}{|c|}{$\begin{array}{l}\text { Heasured Activity } \\
\text { (Counts/s) }\end{array}$} \\
\hline & & Side 1 & Side 2 & Side 3 & Side 4 & Tota 1 \\
\hline$A-72$ & 18.47 & 101 & 72 & 80 & 109 & 362 \\
\hline$A-54$ & 20.81 & 137 & 132 & 161 & 176 & 606 \\
\hline$A-74$ & 20.84 & 135 & 141 & 152 & 166 & 594 \\
\hline$A-73$ & 20.91 & 140 & 133 & 154 & 171 & 598 \\
\hline$D-31$ & 23.43 & 134 & 152 & 187 & 161 & 634 \\
\hline$c-32$ & 23.57 & 115 & 86 & 100 & 159 & 460 \\
\hline$D-26$ & 26.91 & 209 & 195 & 262 & 308 & 974 \\
\hline$c-51$ & 28.90 & 209 & 216 & 293 & 323 & 1045 \\
\hline B-52 & 31.71 & 456 & 436 & 491 & 569 & 1952 \\
\hline$c-52$ & 32.82 & 524 & 397 & 374 & 541 & 1836 \\
\hline$c-70$ & 33.08 & 365 & 432 & 573 & 563 & 1933 \\
\hline$c-72$ & 37.85 & 700 & 605 & 711 & 910 & 2926 \\
\hline$c-56$ & 40.07 & 790 & 780 & 939 & 1056 & 3565 \\
\hline$C-64$ & 40.55 & 868 & 855 & 917 & 1016 & 3656 \\
\hline
\end{tabular}

$a_{A 11}$ the measured rates were corrected to time of discharge from the reactor using the 18.1-yr half-life of ${ }^{244} \mathrm{~cm}$.

beasurement precisions were better than 18 for all fuel assemblies.

0.128 of the ${ }^{242} \mathrm{~cm}$ present at time of discharge would still be present at the time of measurement.

Figure 15 shows a plot of the individual measurenents for each side of the fuel assemblies. Maxinum variability occurs for fuel assembly c-32, which varies from -25 to +24 t of its arerage value. The measurements of the fuel assemblies varied significantly from their average values.

Table IX gives similar measured neutron results for the corner v-detector. Figure 16 shows that the $\mathrm{C}-32$ and $\mathrm{C}-72$ fuel assemblies again have the maximm variability with $c-32$ varying from -22 to +28 and $c-72$ varying from -12 to +138. In Sec. IV.C.5, we quantify the effect of this angular variability upon the verification of exposure of the individual fuel asseablies. 


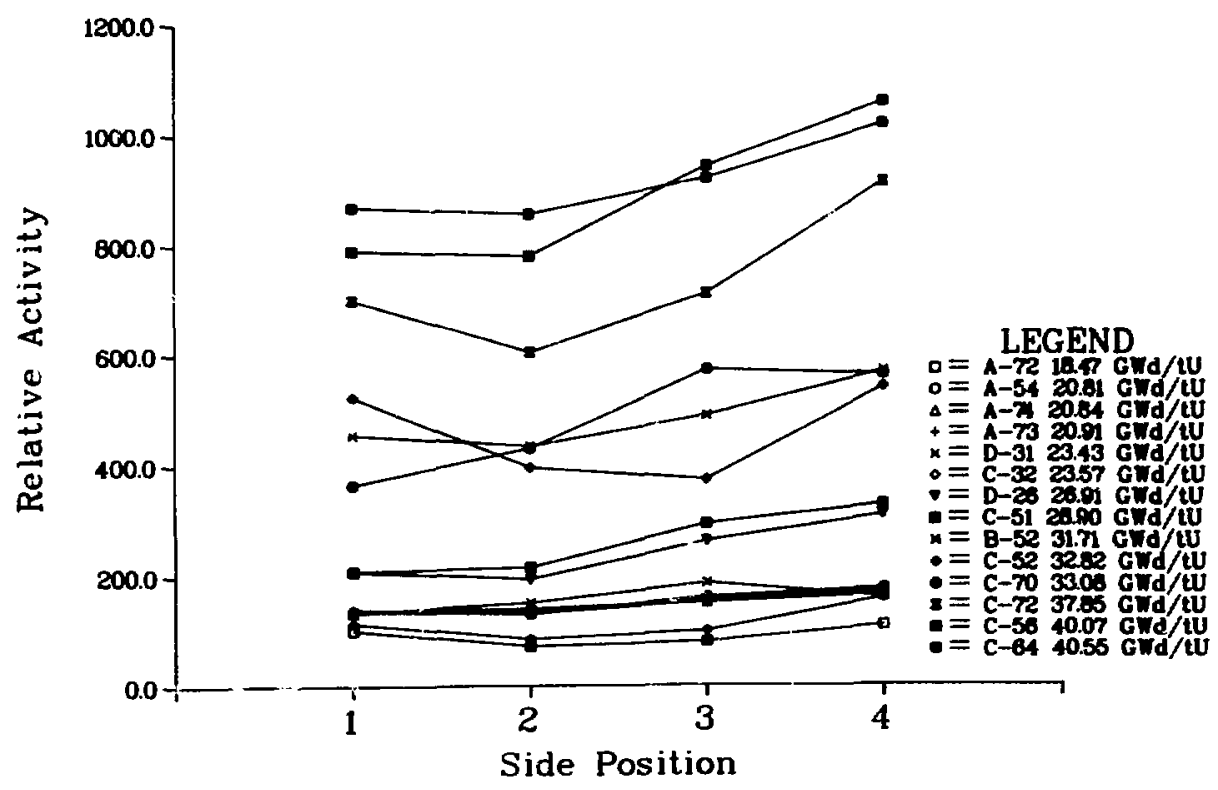

Fig. 15. Measured neutron activities for each side of the 14 irradiated fuel assemblies. The count rates were corrected to time of discharge using the 18.1-yr half-life of $244 \mathrm{~cm}$.

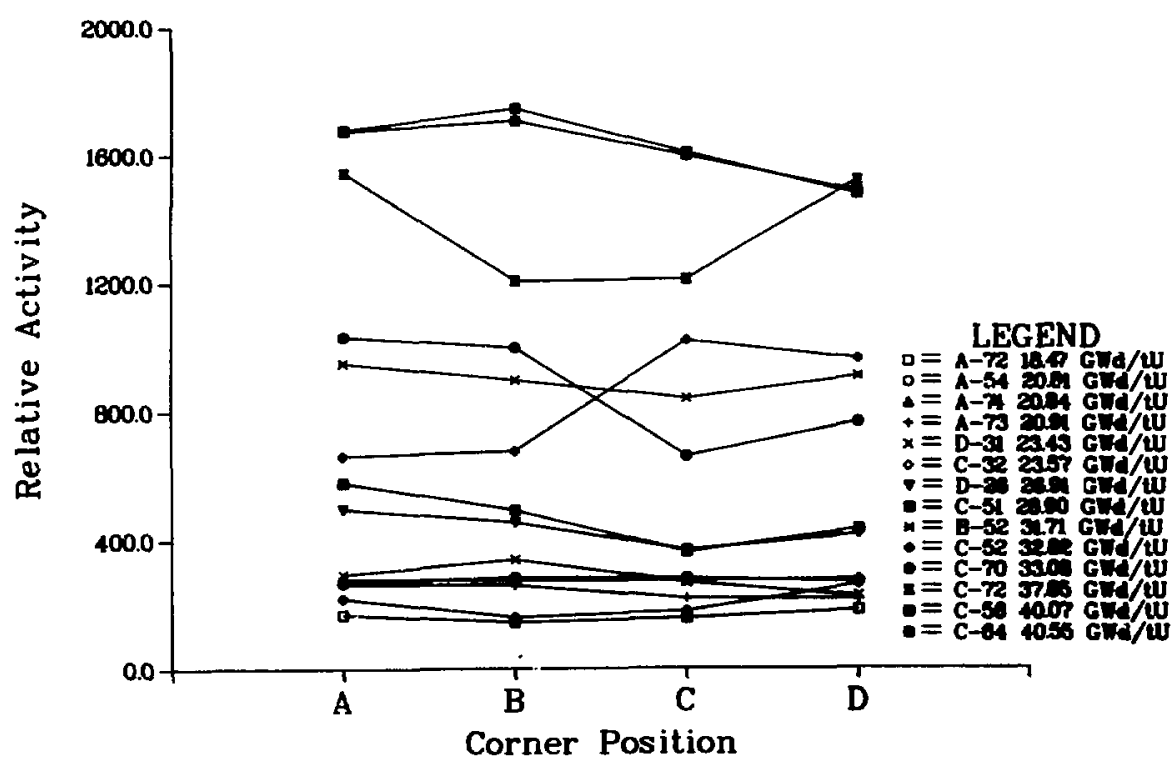

Fig. 16. Measured neutron activities for each corner of the 14 irradiated fuel assemblies. The count rates were corrected to tiwe of discharge using the 18.1-yr half-life of $244 \mathrm{Ca}$. 
TABLE IX

MEASURED NEUTRON RESUL:'S FOR THE CORNER V-DETECTOR

\begin{tabular}{|c|c|c|c|c|c|c|}
\hline \multirow{2}{*}{$\begin{array}{l}\text { Fuel } \\
\text { Assembly }\end{array}$} & \multirow{2}{*}{$\begin{array}{l}\text { Declared } \\
\text { Exposure } \\
\text { (GWd/tU) } \\
\end{array}$} & \multicolumn{5}{|c|}{$\begin{array}{l}\text { Measured Activitya } \\
\text { (Counts/s) }\end{array}$} \\
\hline & & Corner A & Corner B & Corner C & Coxner D & Tota ${ }^{b}$ \\
\hline$A-72$ & 18.47 & 167 & 143 & 155 & 180 & 645 \\
\hline$A-54$ & 20.81 & 267 & 281 & 278 & 268 & 1094 \\
\hline$A-74$ & 20.84 & 277 & 273 & 272 & 276 & 1094 \\
\hline$A-73$ & 20.91 & 263 & 258 & 216 & 215 & 952 \\
\hline$D-31$ & 23.43 & 292 & 338 & 266 & 224 & 1120 \\
\hline$c-32$ & 23.57 & 218 & 159 & 177 & 260 & 814 \\
\hline$D-26$ & 26.91 & 498 & 455 & 367 & 416 & 1736 \\
\hline$c-51$ & 28.90 & 580 & 493 & 361 & 433 & 1867 \\
\hline$B-52$ & 31.71 & 949 & 896 & 839 & 908 & 3592 \\
\hline$c-52$ & 32.82 & 662 & 676 & 1021 & 963 & 3322 \\
\hline$c-70$ & 33.08 & 1032 & 998 & 660 & 765 & 3455 \\
\hline$c-72$ & 37.85 & 1543 & 1204 & 1210 & 1520 & 5477 \\
\hline$c-56$ & 40.07 & 1677 & 1743 & 1606 & 1476 & 6502 \\
\hline$c-64$ & 40.55 & 1674 & 1705 & 1596 & 1485 & 6460 \\
\hline
\end{tabular}

$a_{\text {All }}$ the measured rates were corrected to time of discharge from the reactor using the $18.1-y r$ half-life of $244 \mathrm{~cm}$.

bMeasurement precisions were better than 18 for ail fuel assemblies.

4. Axial Neutron Profiles. The axial neutron profiles were masured for four fuel assemblies with declared exposures ranging from 18.47 to $31.71 \mathrm{GNd}$ tU. The neutron emission rates were measured at 30-cm intervals over tne active fuel region. Figure 17 shows the axial profiles for each of the four sides of the fuei assemblies. As noted in Table VIII and Fig. 15, the neutron signal varies considerably from one side to another. The effect of the differences in the neutron enission rates is discussed in Sec. II.C.5.

These measurements demonstrate the relatively flat profile through the central regions of each fuel assembly. All of our subeequent masurenent: were performed in the $-60-$ to $+60-\mathrm{cm}$ region. 
$\stackrel{\omega}{N}$
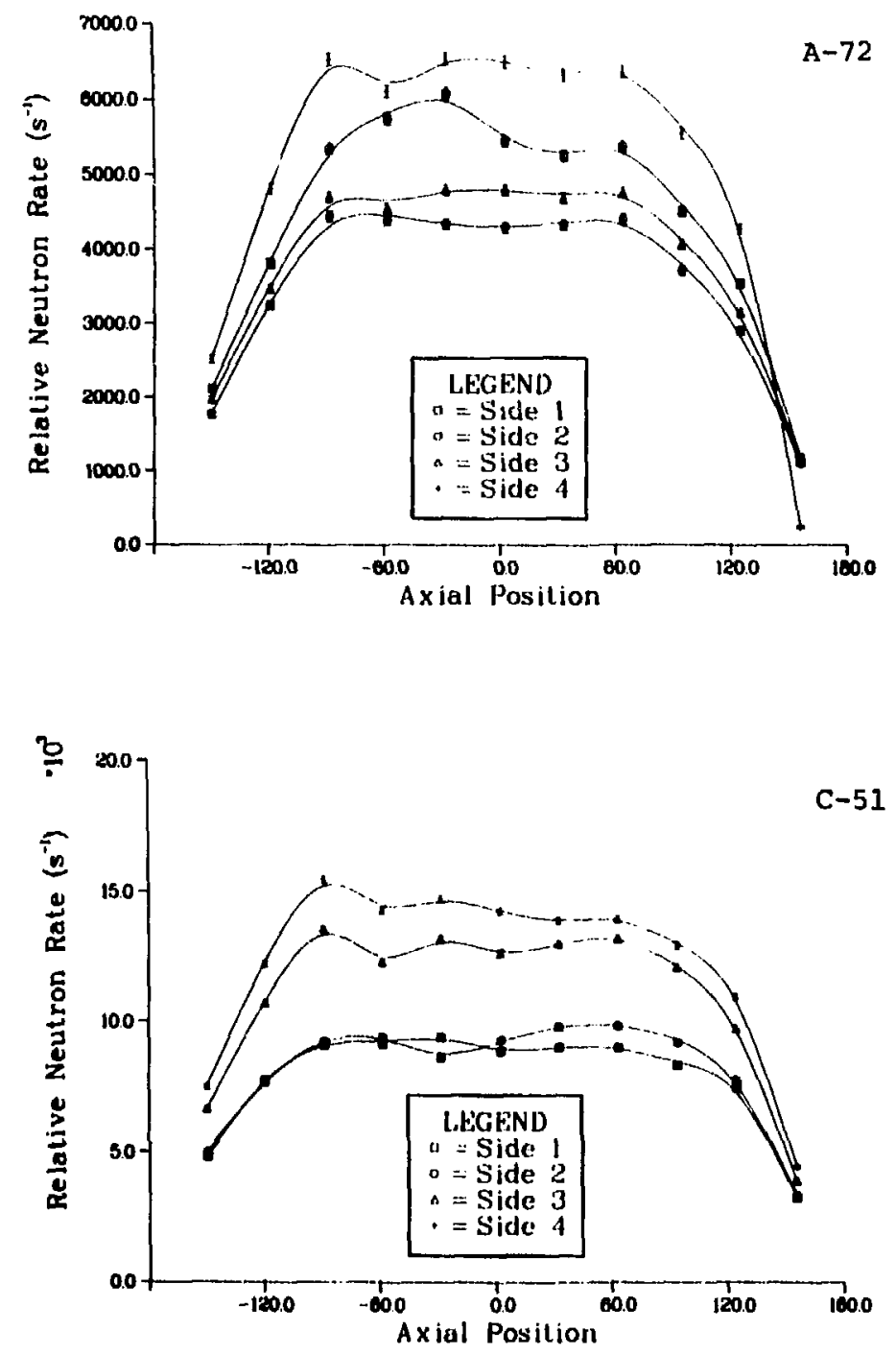
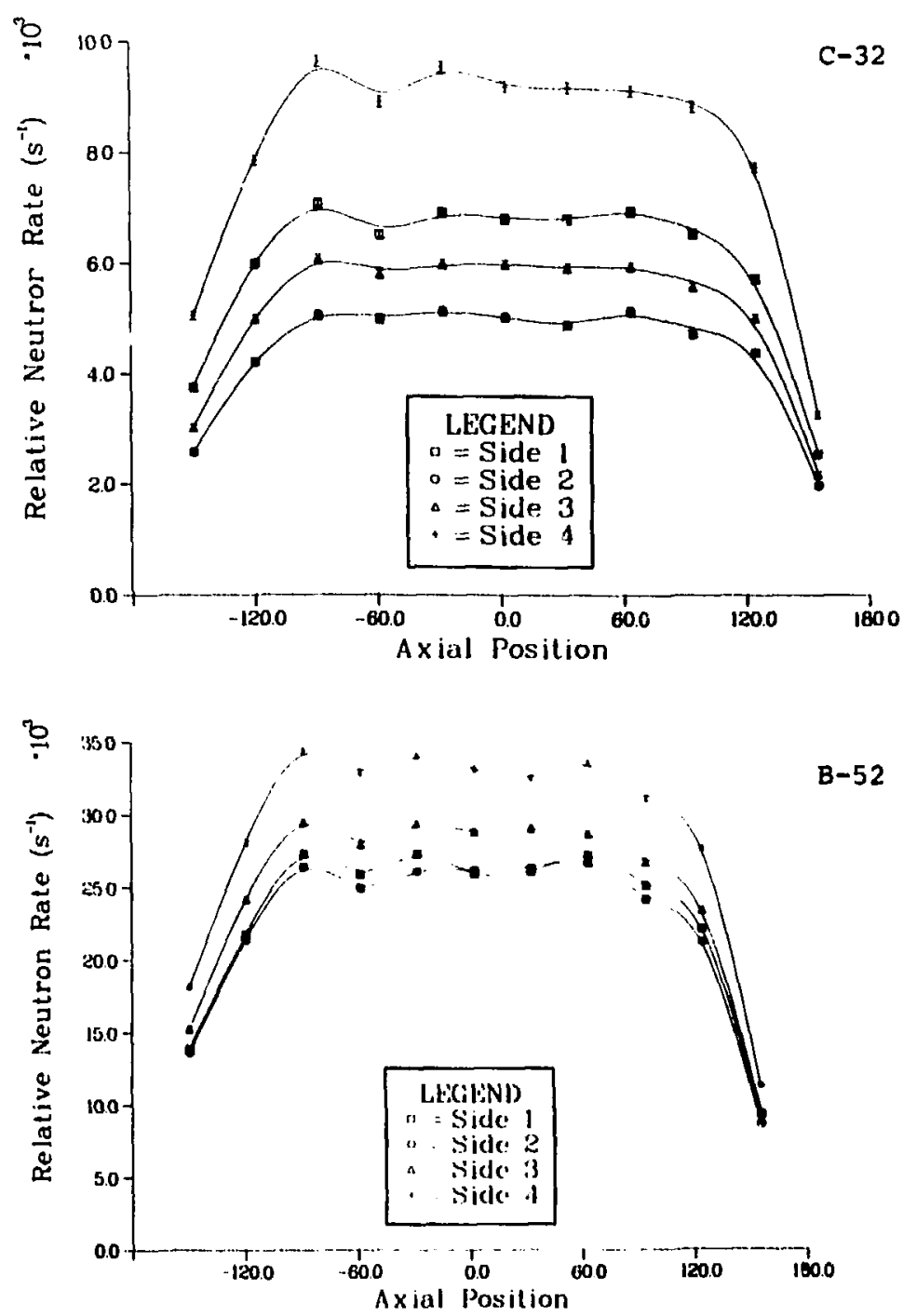

7ig. 17. Axial noutron profiles for each side of the four fuel assemblies: A-72 (18.47 $\mathrm{Gd} / \mathrm{tU})$, $\mathrm{C}-32(23.57 \mathrm{Gdd} / \mathrm{tU}), \mathrm{C}-51(28.90 \mathrm{GNd} / \mathrm{tU})$, and $\mathrm{B}-52$ (31.71 $\mathrm{G} \mathrm{Ad} / \mathrm{tU})$. 
5. Correlation Between Measured Neutron Rates and Declared Exposures. We evaluated the use of a power functional relationship for correlating the measured neutron emission rates of irradiated fuel assenblies with operatordeclared values of exposure. The total neutron rates vs operator-declared values of exposure are plotted in Fig. 18. The average difference between the least squares fitted line and the declared values was 4.2\%. Similar results were obtained when data from only one side at a time were used in the analysis (Table $X$ ). Average absolute differences ranged between 3.6 and 6.3 for the individual side measurements.

Similar results were obtained using the corner v-detector (Fig. 19 and Table XI) with the average absolute differences ranging from 4.3 to 6.65 for the individual corner measurements and being $4.1 \%$ for the sumed data.

Table XII presents couparisons of the two detector systens and evaluates various combinations of detector arrangenents. The first set for the side measurements includes the data from Table $x$, in which only one side detector was analyzed. The second set gives the results for fission chambers placed on opposite sides of the fuel assembly to simulate a "fork" detector. The third set simulates a V-shaped detector with horizontal fission chambers. A threesided detector arrangement corresponds to the fourth set, and a square ringdetector corresponds to the fifth set. The average differences range from 3.6 to 6.38 without regard to the detector measurement geometry. Besults for the corner measurements were very similar with the differences ranging from 4.3 to 6.67. For each type of detector, the average percentage difference appears to improve as we move from one detector to two detectors on adjacent sides or corners, to three detectors, to two detectors on opposite sides or corners, and to four detectors.

We have already discussed the variability of measurements at one axial position for the same fuel assembly. If we use the power functional relationship obtained from the four sides or four corners, we then can use the aximan variability in the count rates to determine the maximu difference in the calculated exposures. In Table XIII the four assemblies with the maxima variability in count rates dewonstrate the magnitude of their effect. Tuble XIII shows that the average error introduced would be in the range of 7 to 84 . Because the operator-declared values are only accurate within to 64,16 angle measurements on one side or one corner would be nearly as accurate. wowever, measuring all four sides (or corners) or cpposite sides cancels wo of the 


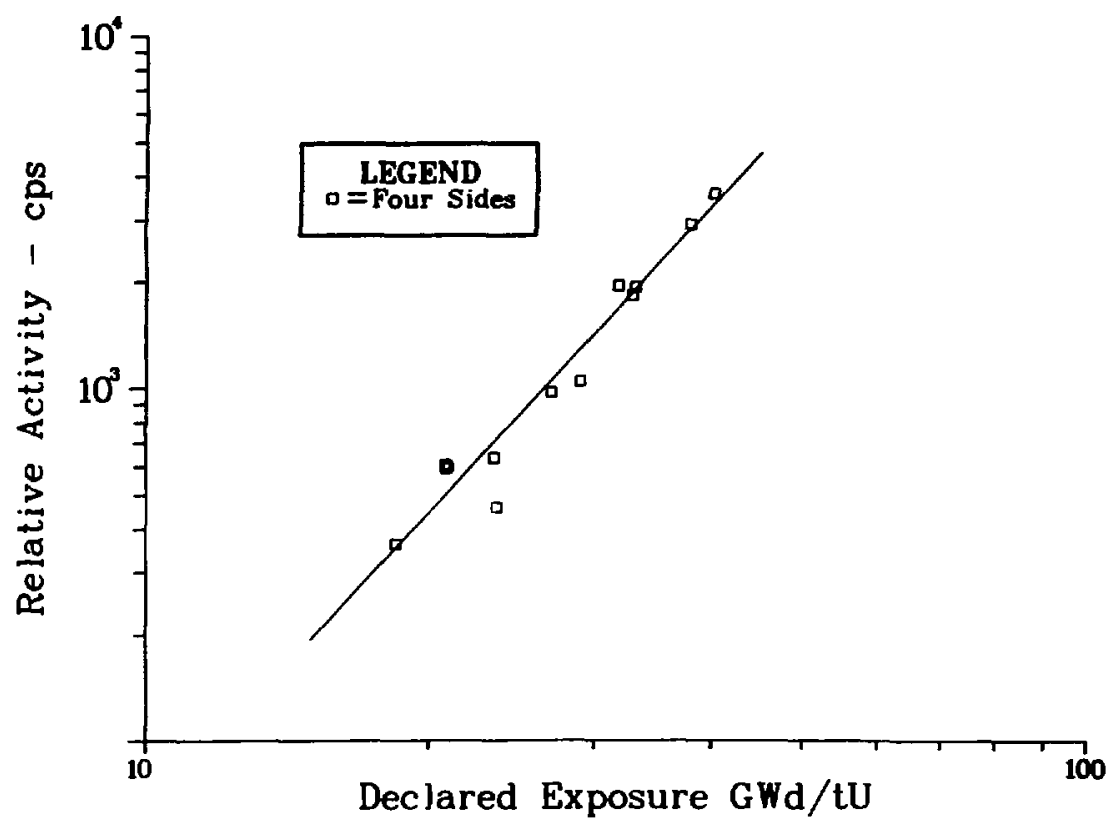

Fig. 18. Measured neutron emission rates using the square-ring detector values vs the operator-declared exposure values for 14 PFR tuel assemblies.

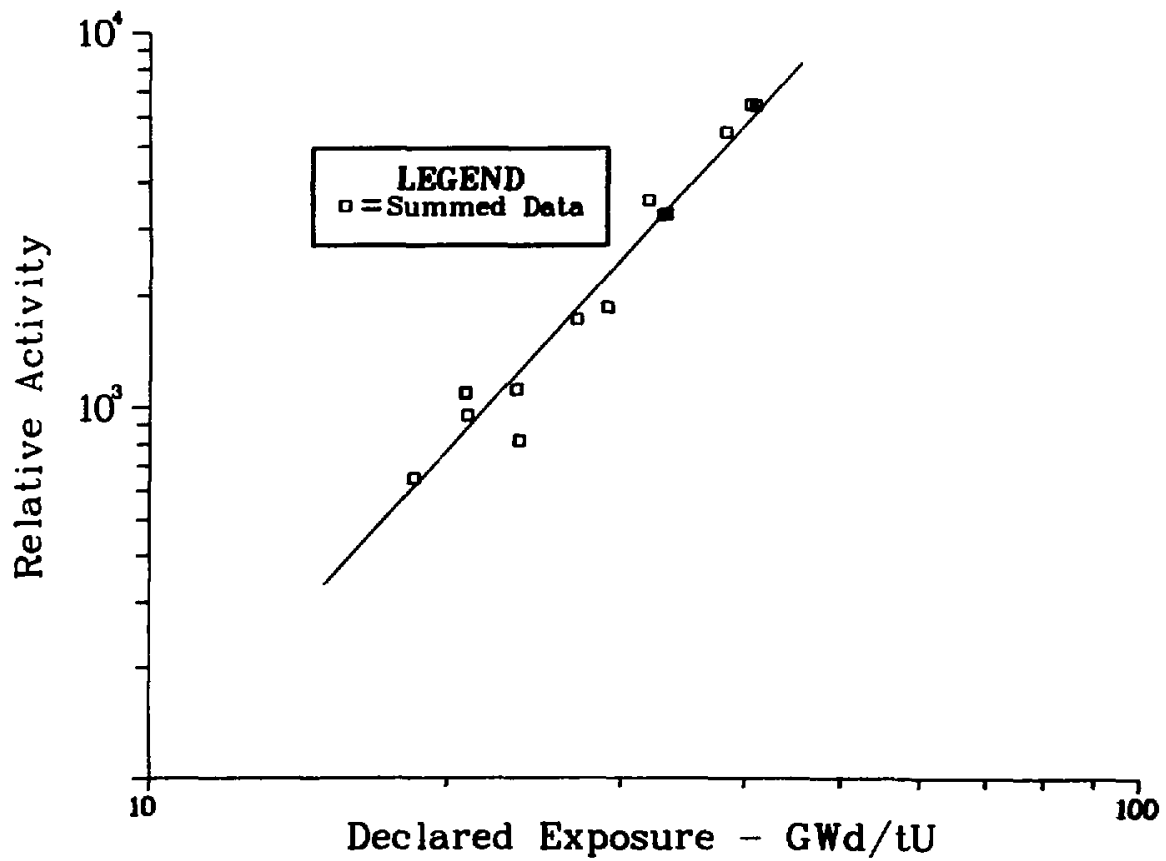

Fig. 19. Wasured neutron enission rates using the V-detector values ve the operator-declared exposure values for 14 PWR fuel assemblies. 
TABLE $\mathbf{x}$

RELATIVE RESULTS BASED ON THE SQUARE-RING MEASURBMETTS

\begin{tabular}{|c|c|c|c|c|c|c|}
\hline \multirow{2}{*}{$\begin{array}{l}\text { Fuel } \\
\text { Assembly }\end{array}$} & \multirow{2}{*}{$\begin{array}{l}\text { Declared } \\
\text { Exposure } \\
\text { (GWd/tU) } \\
\end{array}$} & \multicolumn{5}{|c|}{ Calculated Values } \\
\hline & & Side 1 & Side 2 & Side 3 & side 4 & Average \\
\hline$A-72$ & 18.47 & 19.72 & 18.19 & 17.82 & 18.76 & 18.61 \\
\hline$A-54$ & 20.81 & 21.96 & $22 \cdot 36$ & 22.64 & 22.13 & 22.24 \\
\hline$A-74$ & 20.84 & 21.85 & 22.87 & 22.20 & 21.68 & 22.09 \\
\hline$A-73$ & 20.91 & 22.13 & 22.42 & 22.30 & 21.91 & 22.14 \\
\hline$D-3 I$ & 23.43 & 21.79 & 23.46 & 23.83 & 21.46 & 22.59 \\
\hline$c-32$ & 23.57 & 20.64 & 19.32 & 19.23 & 21.37 & 20.22 \\
\hline$D-26$ & 26.91 & 25.50 & 25.54 & 26.74 & 26.82 & 26.20 \\
\hline$C-51$ & 28.90 & 25.50 & 26.45 & 27.88 & $27 \cdot 38$ & 26.84 \\
\hline B-52 & 31.71 & 33.61 & 33.61 & 33.16 & 33.12 & 33.31 \\
\hline$c-52$ & 32.82 & 35.31 & $32 \cdot 55$ & 30.21 & 32.55 & 32.61 \\
\hline$c-70$ & 33.08 & 31.07 & 33.50 & 34.96 & 33.00 & 33.20 \\
\hline$c-72$ & 37.85 & 39.12 & 37.58 & 37.64 & 38.93 & 38.31 \\
\hline$c-56$ & 40.07 & 40.83 & 40.98 & 41.40 & 40.97 & 41.01 \\
\hline$c-64$ & 40.55 & 42.21 & 42.28 & 41.07 & 40.43 & 41.37 \\
\hline \multicolumn{2}{|c|}{$\begin{array}{l}\text { Average absolute } \\
\text { difference (\$) }\end{array}$} & 6.3 & 5.2 & 5.2 & 3.6 & 4.2 \\
\hline \multicolumn{7}{|c|}{ Power function parameter } \\
\hline \multicolumn{2}{|c|}{$R^{2}$} & 0.9296 & 0.9248 & 0.9266 & 0.9671 & 0.9527 \\
\hline \multicolumn{2}{|c|}{$\alpha$} & 0.02213 & 0.01456 & 0.01776 & 0.02161 & 0.07622 \\
\hline \multicolumn{2}{|c|}{ B } & 2.826 & 2.933 & 2.921 & 2.908 & 2.985 \\
\hline
\end{tabular}

$a_{R}{ }^{2}$ is the correlation coefficient. When multiplied by 100 , it represente the percentage of the total mean variation explained by the regression. 
TABLE XI

RELATIVE RESULTS BASED ON THE CORNER V-DETECTOR MEASUREATATS

\begin{tabular}{|c|c|c|c|c|c|c|}
\hline \multirow{2}{*}{$\begin{array}{l}\text { Fuel } \\
\text { Assembly }\end{array}$} & \multirow{2}{*}{$\begin{array}{l}\text { Declared } \\
\text { Exposure } \\
\text { (GNa/tU) }\end{array}$} & \multicolumn{5}{|c|}{ Calculated Values } \\
\hline & & Corner $\mathrm{A}$ & Corner B & Corner C & Corner D & Average \\
\hline $\mathrm{A}-72$ & 18.47 & 18.63 & 18.07 & 18.93 & 19.39 & 18.73 \\
\hline$A-54$ & 20.81 & 21.83 & 22.68 & 23.08 & 22.24 & 22.40 \\
\hline$A-74$ & 20.84 & 22.10 & 22.46 & 22.91 & 22.47 & 22.43 \\
\hline$A-73$ & 20.91 & 21.72 & 22.03 & 21.19 & 20.61 & $21 \cdot 37$ \\
\hline$D-31$ & 23.43 & 22.50 & 24.13 & 22.74 & 20.91 & 22.59 \\
\hline$c-32$ & 23.57 & 20.39 & 18.73 & 19.80 & 22.01 & 20.27 \\
\hline$D-26$ & 26.91 & 26.94 & 26.66 & 25.37 & 25.89 & 26.20 \\
\hline$c-51$ & 28.90 & 28.37 & 27.39 & 25.23 & 26.25 & 26.86 \\
\hline B-52 & 31.71 & 33.49 & 33.48 & 33.60 & 33.89 & 33.53 \\
\hline$c-52$ & 32.82 & 29.66 & 30.45 & 30.92 & 34.58 & 32.65 \\
\hline$c-70$ & 33.08 & 34.45 & 34.71 & 30.97 & 31.94 & 33.09 \\
\hline$c-72$ & 37.85 & 39.46 & 36.97 & 38.05 & 40.48 & 38.69 \\
\hline$c-56$ & 40.07 & 40.59 & 41.87 & 41.90 & 40.07 & 41.00 \\
\hline$c-64$ & 40.55 & 40.56 & 41.56 & 41.81 & 40.16 & 40.91 \\
\hline \multicolumn{6}{|c|}{ Average absolute } & 4.1 \\
\hline \multicolumn{7}{|c|}{ Power functicn paraneters } \\
\hline $\mathbf{R}^{2}$ & & 0.9531 & 0.9138 & 0.9087 & 0.9445 & 0.9524 \\
\hline$\alpha$ & & 0.02875 & 0.02597 & 0.02707 & 0.03342 & 0.11432 \\
\hline B & & 2.963 & 2.976 & 2.942 & 2.898 & 2.948 \\
\hline
\end{tabular}

$a_{R^{2}}$ is the correlation coefficient. When multiplied by 100 , it represents the percentage of the total mean variation explained by the regression. 
TABLE XII

COMPARISON OF THE TWO MEASUREMENT GEOMETRIES

\begin{tabular}{|c|c|c|c|c|c|}
\hline $\begin{array}{l}\text { Data } \\
\text { Set } \\
\end{array}$ & Measurement & $\mathrm{R}^{2}$ & $\begin{array}{l}\text { Parameter } \\
\text { Value } \\
\alpha \\
\end{array}$ & $\boldsymbol{B}$ & $\begin{array}{l}\text { Average } \\
\text { Difference } \\
\text { (\$) } \\
\end{array}$ \\
\hline 1 & $\begin{array}{l}\text { Side } 1 \\
\text { Side } 2 \\
\text { Side } 3 \\
\text { Side } 4\end{array}$ & $\begin{array}{l}0.9296^{a} \\
0.9248 \\
0.9266 \\
0.9671\end{array}$ & $\begin{array}{l}0.02213 \\
0.01456 \\
0.01776 \\
0.02161\end{array}$ & $\begin{array}{l}2.826 \\
2.933 \\
2.921 \\
2.908\end{array}$ & $\begin{array}{l}6.3 \\
5.2 \\
5.2 \\
3.6\end{array}$ \\
\hline 2 & $\begin{array}{l}\text { Sides } 1 \text { and } 3 \\
\text { Sides } 2 \text { and } 4\end{array}$ & $\begin{array}{l}0.9471 \\
0.9569\end{array}$ & $\begin{array}{l}0.03964 \\
0.03663\end{array}$ & $\begin{array}{l}2.876 \\
2 \cdot 915\end{array}$ & $\begin{array}{l}4.3 \\
4.1\end{array}$ \\
\hline 3 & $\begin{array}{l}\text { Sides } 1 \text { and } 2 \\
\text { Sides } 2 \text { and } 3 \\
\text { Sides } 3 \text { and } 4 \\
\text { Sides } 4 \text { and } 1\end{array}$ & $\begin{array}{l}0.9357 \\
0.9295 \\
0.9584 \\
0.9566\end{array}$ & $\begin{array}{l}0.03663 \\
0.03218 \\
0.03993 \\
0.04332\end{array}$ & $\begin{array}{l}2.874 \\
2.928 \\
2.911 \\
2.873\end{array}$ & $\begin{array}{l}5.4 \\
5.2 \\
4.0 \\
4.7\end{array}$ \\
\hline 4 & $\begin{array}{l}\text { Sides } 1,2, \text { and } 3 \\
\text { Sides } 2,3, \text { and } 4 \\
\text { Sides } 3,4, \text { and } 1 \\
\text { sides } 4,1, \text { and } 2\end{array}$ & $\begin{array}{l}0.9412 \\
0.9516 \\
0.9579 \\
0.9530\end{array}$ & $\begin{array}{l}0.05416 \\
0.05455 \\
0.06150 \\
0.05833\end{array}$ & $\begin{array}{l}2.892 \\
2.916 \\
2.886 \\
2.887\end{array}$ & $\begin{array}{l}4.5 \\
4.3 \\
4.0 \\
4.6\end{array}$ \\
\hline 5 & $\begin{array}{l}\text { All four sides } \\
\text { Corner Measureaent }\end{array}$ & 0.9527 & 0.07622 & 2.895 & 4.2 \\
\hline 1 & $\begin{array}{l}\text { Corner A } \\
\text { Corner B } \\
\text { Corner C } \\
\text { Corner D }\end{array}$ & $\begin{array}{l}0.9513 \\
0.9138 \\
0.9087 \\
0.9445\end{array}$ & $\begin{array}{l}0.02876 \\
0.02597 \\
0.02707 \\
0.03342\end{array}$ & $\begin{array}{l}2.963 \\
2.976 \\
2.942 \\
2.898\end{array}$ & $\begin{array}{l}4.3 \\
5.8 \\
6.6 \\
5.4\end{array}$ \\
\hline 2 & $\begin{array}{l}\text { Corners } A \text { and } C \\
\text { Corners } B \text { and } D\end{array}$ & $\begin{array}{l}0.9499 \\
0.9544\end{array}$ & $\begin{array}{l}0.05436 \\
0.06011\end{array}$ & $\begin{array}{l}2.963 \\
2.933\end{array}$ & $\begin{array}{l}4.3 \\
4.1\end{array}$ \\
\hline 3 & $\begin{array}{l}\text { Corners } A \text { and } B \\
\text { Corners } B \text { and } C \\
\text { Corners } C \text { and } D \\
\text { Corners } D \text { and } A\end{array}$ & $\begin{array}{l}0.9390 \\
0.9264 \\
0.9356 \\
0.9628\end{array}$ & $\begin{array}{l}0.05498 \\
0.05226 \\
0.06062 \\
0.06160\end{array}$ & $\begin{array}{l}2.968 \\
2.965 \\
2.919 \\
2.933\end{array}$ & $\begin{array}{l}4.6 \\
4.8 \\
5.8 \\
4.0\end{array}$ \\
\hline 4 & $\begin{array}{l}\text { Corners } \mathrm{A}, \mathrm{B}, \text { and } C \\
\text { Corners } \mathrm{B}, \mathrm{C}, \text { and } \mathrm{D} \\
\text { Corners } \mathrm{C}, \mathrm{D}, \text { and } \mathrm{A} \\
\text { Corners } \mathrm{D}, \mathrm{A}, \text { and } \mathrm{B}\end{array}$ & $\begin{array}{l}0.9432 \\
0.9446 \\
0.9543 \\
0.9571\end{array}$ & $\begin{array}{l}0.08046 \\
0.08650 \\
0.08795 \\
0.08838\end{array}$ & $\begin{array}{l}2.967 \\
2.939 \\
2.940 \\
2.945\end{array}$ & $\begin{array}{l}4.3 \\
4.7 \\
4.5 \\
4.2\end{array}$ \\
\hline 5 & All four corners & 0.9524 & 0.11432 & 2.948 & 4.1 \\
\hline
\end{tabular}

$a_{R}{ }^{2}$ is the correlation conficient. When multiplied by 100 , it repreaent: the percentage of the total man variation explained by the regreasion. 
TABLE XIII

EFFECT OF VARIABCI.ITY IN COUNTING RATES ON CALCULATED EXPOSURES USING THE PONER FUICTIONAT RELATIONSHIP

\begin{tabular}{|c|c|c|c|c|}
\hline $\begin{array}{l}\text { Fuel } \\
\text { Assembly } \\
\text { Measurements }\end{array}$ & sid/c! & $\begin{array}{l}\text { Range in } \\
\text { Measured } \\
\text { hetivities } \\
\text { (Counts/s) } \\
\end{array}$ & $\begin{array}{l}\text { Range in } \\
\text { Calculated } \\
\text { Exposures } \\
\text { (GNd/tU) }\end{array}$ & $\begin{array}{c}\text { Difference } \\
\text { (1) }\end{array}$ \\
\hline \multicolumn{5}{|l|}{ Side } \\
\hline$c-32$ & 18.47 & $86-159$ & $18.30-22.63$ & -1.0 to 22.5 \\
\hline $\mathrm{C}-70$ & 33.08 & $365-573$ & $30.14-35.23$ & -8.9 to 6.5 \\
\hline$c-72$ & 37.85 & $605-910$ & $35.89-41.33$ & -5.2 to 9.2 \\
\hline$c-56$ & 40.07 & $780-1056$ & $\begin{array}{c}39.19-43.51 \\
\text { Average }\end{array}$ & $\begin{array}{c}-2.2 \text { to } 8.6 \\
8.0\end{array}$ \\
\hline \multicolumn{5}{|l|}{ Corner } \\
\hline$c-32$ & 18.47 & $159-260$ & $18.64-22.02$ & 5.5 to 19.2 \\
\hline$c-70$ & 33.08 & $660-1032$ & $30.21-35.16$ & -8.7 to 6.3 \\
\hline$c-72$ & 37.85 & $1210-1543$ & $37.11-40.30$ & -2.0 to 6.5 \\
\hline$c-56$ & 40.07 & $1476-1677$ & $39.69-41.45$ & -10 to 3.4 \\
\hline & & & Average & 6.6 \\
\hline
\end{tabular}

assembly-positioning uncertainties. Positioning was controlled better in the present work than we could expect under normal inspection conditions. Thus, tine single side (or corner) results look better than wight be the normal case.

6. Position Seneitivity for the Square-Ring Detector. To determine the position sensitivity of the fuel assenbly within the square-ring detector, fuel assenbly B-52 (31.71 GNd/tU) was positioned at 11 different locations, and the neutron rates were neasured for each of the four fiseion chanbers. These positions varied from the center, to the aide, to the corners to obtain the maxim count rate changes (Table XIV).

The count rates for a specific finsion chamber could vary significantly (698.8 to 989.3 counts/s for side 1 ); however, the total counts for all four siden varied only an average of 3.78. Part of this variation is due to a decrease in the fission counter efficiency from water displacement as the 
POSITION SENSITIVITY FOR NEUTRON MEASUREMENTS USING THE SQUARE-RING DETECTOR ${ }^{2}$

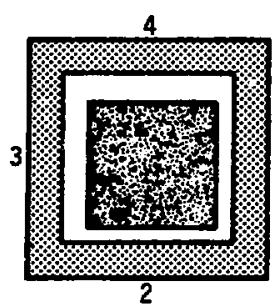

Side 1925.7

Side 2942.9

I Side 3899.0

Side 4894.3

Tota1 3661.9

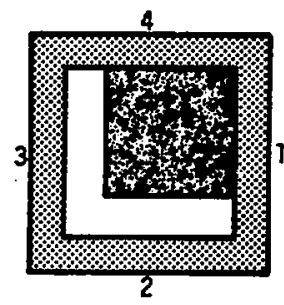

Side 1950.3

side 2758.8

I Side $3 \quad 739.3$

Side 4919.3

Total 3367.7
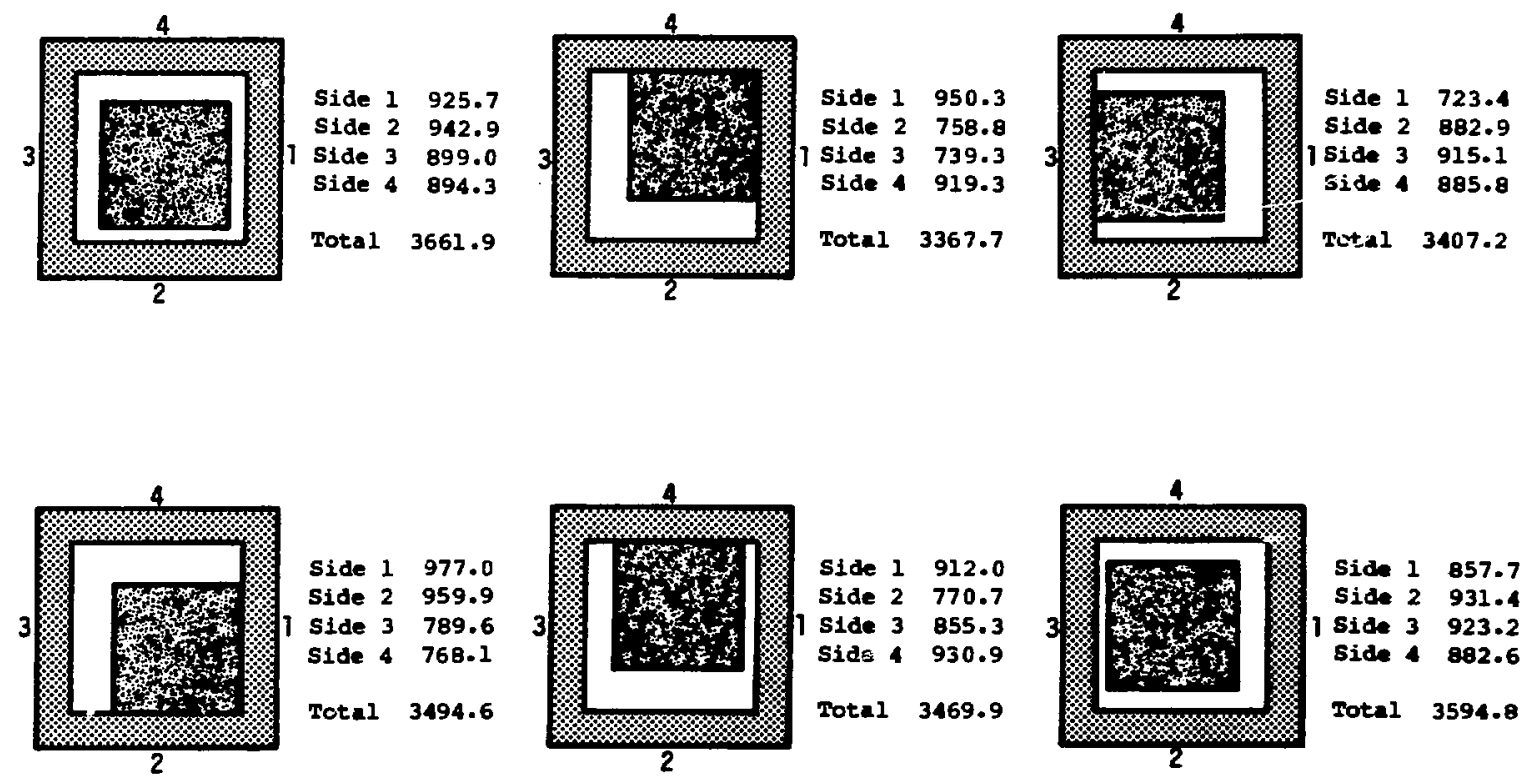

Side 1977.0

Side 2959.9

Side 3789.6

side 4768.1

Total 3494.6

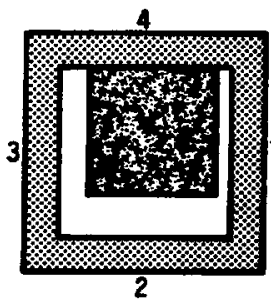

Side 1912.0

Side $2 \quad 770.7$

1 side 3 B55.3

Side 4930.9

Total 3469.9

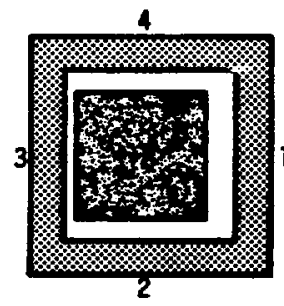

Side 1 857.7

Side 2931.4

1 side 3923.2

Side 882.6

Total 3594.8

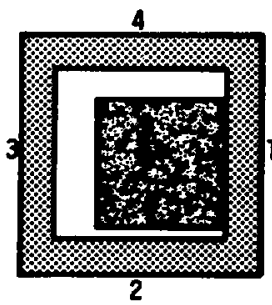

Side 1984.5

side 2930.0

side 3782.8

side 4 B83.4

Total 3580.7

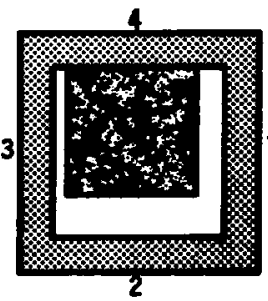

side 1719.4

Side 2760.2

I stde $3 \quad 895.6$

side 916.2

Total 3291.4

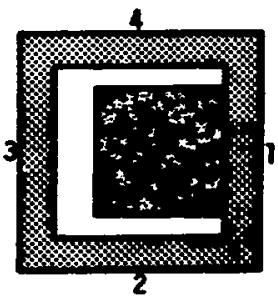

Eide 1909.3

ide 2923.3

$\therefore=3 \quad 010.5$

Side 452.2

Total 3575.3

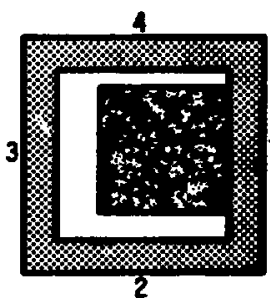

Bide 1964.1

side 2701.6

1 side 3747.0

side 416.3

Total 3409.0

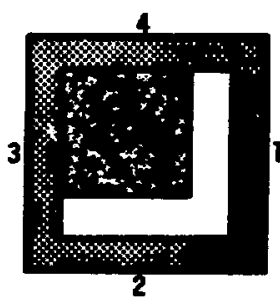

Iida 1 699.8

side 2766.6

1 side $3 \quad 97.9$

side 921.1

Total 3244.4

Ararase total $3467.0 \pm 125.0$

(3.70)

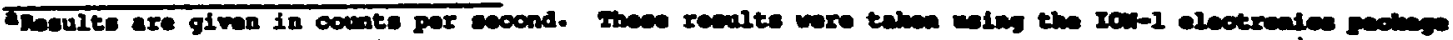
with a threshold wetting of 24 . 
assembly is moved next to the side wall of the square ring. Polyethylene and cadiuiun will be placed around each detector in future models to eliminate this effect.

V. GROSS GAMLA MEASUREMENTS

The capacity of the square-ring detector to measure simultaneously the gross gama-ray doses from the four sides of an irradiated fuel assenbly was evaluated at the Morris Facility. Measurements similar to those described in Sec. Iv included the following.

- Reproducibility measurements for estimation of precision.

- Measurement of each side of an individual fuel assembly to deternine the variability of source strengths.

- Comparison with measurements using the two detector system.

- Correlation between the declared cooling time and the measured dose.

Both the ION-1 electronics unit and the microprocessor unit recorded the data. The responses of the ion chambers were not calibrated and therefore are only relative numbers. From prior work we have established that the ion chambers do operate linearly, that is, a twofold increase in gross gama-ray activity results in a twofold increase in the measured signal.

A. Origins of Gross Gama-Ray Sources

Table XV lists the fission product and activation product isotopes that are the principal sources of the gross gama-ray signal in irradiated fuel assemblies. Two of the shielded isotopes, ${ }^{134} \mathrm{Cs}$ and ${ }^{154} \mathrm{Eu}$, are produced primarily through a secondary reaction. They are not produced primarily by fission but rather by fission followed by one or more neutron captures. Because of complicated production chains, different half-lives, and different fission yields, it is extremely difficult to relate the gross gamaray doses to operator-declared exposures.

\section{B. Reproducibility Neasurements}

Repeated measurements of the C-32 irradiated fuel assombly gave a precision of 1.3\%, which is slightly bettex than the comparable precision of the neutron measurements (Trables VI and VII). 
TABLE XV

MEASURABLE ISOTOPES IN TYPICAT IWR EUEL ASSEMBLIES

Fission Yield

Fission Product

Isotop
$137 \mathrm{Cs}$
$154 \mathrm{Eua}$
$-25 \mathrm{Sb}$

Half-Life

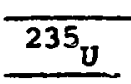

(\$)

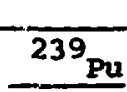

$30.17 \mathrm{yr}$

6.222

8.5 yr

$2 \cdot 69-6^{b}$

6.689

$9 \cdot 22-5$

$2.71 \mathrm{yr}$

0.0294

0.1110

$1.1 \mathrm{Cs}^{\mathrm{a}}$

2.062 yr

$1 \cdot 27-5$

$9 \cdot 89-4$

$106_{\mathrm{Ru}-\mathrm{Rh}}$

$$
366.4 \text { days }
$$

0.4018

4.280

$144 \mathrm{Ce}-\mathrm{Pr}$

$$
\Sigma 84.5 \text { days }
$$

5.475

3.736

$95 \mathrm{zr}$

$$
63.98 \text { days }
$$

6.496

4.892

6.948

39.35 days $\quad 3.043$

34.97 days $\quad 6.496$

4.893
Gama-Ray Energy (kev) [Branching Ratio]

$661.6[0.851]$

$1274.4[0.355], 1004.8[0.174]$, $996.3[0.103]$

$427.9[0.30], 600.8[0.18]$, $686.2[0.12], 463.5[0.11]$

$604.7[0.976], 795.8[0.854]$, $801.8[0.087], 1365.1[0.0304]$. $1167.9[0.018]$

$$
\begin{aligned}
& 622.2[0.098], 1050.5[0.016] \\
& 696.5[0.0134], 2185.6[0.0066], \\
& 1489.2[0.0026] \\
& 756.7[0.546], 724.2[0.431] \\
& 497.1[0.864], 610.3[0.054] \\
& 765.8[0.9982]
\end{aligned}
$$

Activation Product

$\begin{array}{lc}{ }^{60} \mathrm{Co} & 5.27 \mathrm{yr} \\ 58^{\mathrm{Co}} & 70.3 \text { days } \\ 54_{\mathrm{Mr}} & 312.2 \text { days }\end{array}$

$1173.2[1.00]$

$1332.5[1.00]$

$811.1[0.99]$,

$511.0^{c}$

$834.8[1.00]$

aEuropium-154 and $134 \mathrm{Cs}$ values are given only for direct production of the isotope from the fission process. Each isotope is produced primarlly through neutron absorption. For PWR fuel material irradiated to $25 \mathrm{Grd} / \mathrm{tU}$, the "accumulated fission yields" of $154 \mathrm{Eu}$ and $134 \mathrm{Cs}$ were calculated as 0.15 and 0.46 for the total fissions, respectively.

$b_{2.69-6}$ should be read as $2.69 \times 10^{-6}$.

$c_{\beta}+$ annihilation gama ray. 
c. Variability in Source Strength at One Axial Location

The measured gross gama-ray doses varied by as much as 30 for the side measurements and 228 for the corner measurements (Tables XVI and XVII). Fuel assemblies $\mathrm{C}-52, \mathrm{C}-70$, and $\mathrm{C}-72$ have the largest variabilities. The direction of the changes from one side or corner to the next is the same as it was for the neutron results; however, the relative magnitudes of the changes for the neutron and gamma-ray data are different. The neutron results vary as a power function of the exposure, and the gama-ray results should vary as a linear function of exposure if one were to ignore the effects of the various halflives of the gamma-emitting isotopes. Thus, the calculated exposure for the neutron case is less sensitive to the counting rate variations. For example, a 108 change in the neutron rate represents only a 38 change in the exposure, whereas a 108 change in the gama-ray rate represents a 10 change in the calculated exposure. Figures 20 and 21 show the two sets of data plotted as a function of measurement position.

TABLE XVI

LEASURED GAYYA-RAY RESULTS FOR THE SQUARE-RING DETECTOR

\begin{tabular}{|c|c|c|c|c|c|c|c|}
\hline \multirow{2}{*}{$\begin{array}{l}\text { Fuel } \\
\text { Assembly }\end{array}$} & \multirow{2}{*}{$\begin{array}{l}\text { Declared } \\
\text { Exposure } \\
\text { (Gdd/tU) } \\
\end{array}$} & \multirow{2}{*}{$\begin{array}{l}\text { Cooling } \\
\text { Time } \\
\text { (Days) } \\
\end{array}$} & \multicolumn{2}{|r|}{ Measured } & Gama-Ray & Dose & \multirow[b]{2}{*}{ Total } \\
\hline & & & Side 1 & Side 2 & Side 3 & Side 4 & \\
\hline$A-72$ & 18.47 & 2445 & 408 & 390 & 457 & 442 & 1697 \\
\hline$A-54$ & 20.81 & 2445 & 523 & 492 & 525 & 518 & 2058 \\
\hline A-74 & 20.84 & 2445 & 516 & 548 & 538 & 465 & 2067 \\
\hline$A-73$ & 20.91 & 2445 & 585 & 513 & 469 & 490 & 2057 \\
\hline$D-31$ & 23.43 & 2049 & 618 & 720 & 748 & 581 & 2667 \\
\hline$c-32$ & 23.57 & 2638 & 585 & 406 & 434 & 572 & 1997 \\
\hline$D-26$ & 26.91 & 2049 & 682 & 809 & 872 & 783 & 3146 \\
\hline$c-51$ & 28.90 & 1947 & 776 & 956 & 924 & 857 & 3513 \\
\hline B-52 & 31.71 & 1947 & 1102 & 1000 & 1026 & 1015 & 4143 \\
\hline$c-52$ & 32.82 & 1575 & 1610 & 1166 & 1017 & 1273 & 5066 \\
\hline$C-70$ & 33.08 & 1575 & 1109 & 1156 & 1560 & 1276 & 5101 \\
\hline$c-72$ & 37.85 & 1575 & 1684 & 1391 & 1461 & 1579 & 6115 \\
\hline$c-56$ & 40.07 & 1575 & 1599 & 1562 & 1692 & 1556 & 6409 \\
\hline$c-64$ & 40.55 & 1575 & 1747 & 1620 & 1572 & 1525 & 6464 \\
\hline
\end{tabular}


TABLE XVII

MEASURED GAMMA-RAY RESUL'SS FOR THE CORNER V-DETECTCR

\begin{tabular}{|c|c|c|c|c|c|c|c|}
\hline \multirow{2}{*}{$\begin{array}{l}\text { Fuel } \\
\text { Assembly } \\
\end{array}$} & \multirow{2}{*}{$\begin{array}{l}\text { Declared } \\
\text { Exposure } \\
\text { (GWd/tU) }\end{array}$} & \multirow{2}{*}{$\begin{array}{l}\text { Cooling } \\
\text { Time } \\
\text { (Days) } \\
\end{array}$} & \multicolumn{2}{|r|}{ Measured } & Gamia-Ray & \multicolumn{2}{|l|}{ Dose } \\
\hline & & & Corner A & Corner B & Corner C & Corner $D$ & Total \\
\hline$A-72$ & 18.47 & 2445 & 214 & 188 & 202 & 224 & 828 \\
\hline$A-54$ & 20.81 & 2445 & 247 & 256 & 258 & 245 & 1006 \\
\hline$A-74$ & 20.84 & 2445 & 253 & 248 & 249 & 252 & 1002 \\
\hline$A-73$ & 20.91 & 2445 & 240 & 240 & 216 & 215 & 911 \\
\hline$D-31$ & 23.43 & 2049 & 334 & 378 & 312 & 268 & 1292 \\
\hline$c-32$ & 23.57 & 2638 & 257 & 186 & 216 & 289 & 948 \\
\hline$D-26$ & 26.91 & 2049 & 418 & 395 & 330 & 361 & 1504 \\
\hline$C-51$ & 28.90 & 1947 & 491 & 443 & 336 & 398 & 1577 \\
\hline B-52 & 31.71 & 1947 & 528 & 508 & 486 & 501 & 2023 \\
\hline$C-52$ & 32.82 & 1575 & 513 & 483 & 681 & 684 & 2361 \\
\hline$C-70$ & 33.08 & 1575 & 710 & 670 & 488 & 584 & 2452 \\
\hline$c-72$ & 37.85 & 1575 & 813 & 684 & 684 & 806 & 2984 \\
\hline$C-56$ & 40.07 & 1575 & 795 & 810 & 774 & 727 & 3106 \\
\hline$C-64$ & 40.55 & 1575 & 812 & 800 & 773 & 738 & 3123 \\
\hline
\end{tabular}

D. Axial Gross Gama-Ray Profiles

The axial gross gama-ray profiles were measured for the same four fuel assemblies shown in Fig. 17 to demonstrate the relative flat response on the central regions of the fuel assemblies. Figure 22 shows the results for each of the four sides of the fuel assemblies. The variability between the measurements of each side is less than was noted in Fig. 17 for the neutron masurements because the gama-ray dose is directly related to the exposure and cooling times, whereas the neutron signal is related to exposure by a power function.

E. Correlation Between Declared Cooling Times and Hoasured Doses

The internal consistency of a set of sinilar fuel assemblies can be verified by calculating the correlation between the measured gama-ray doeed divided by the declared exposure ve the declared cooling time of the funl 


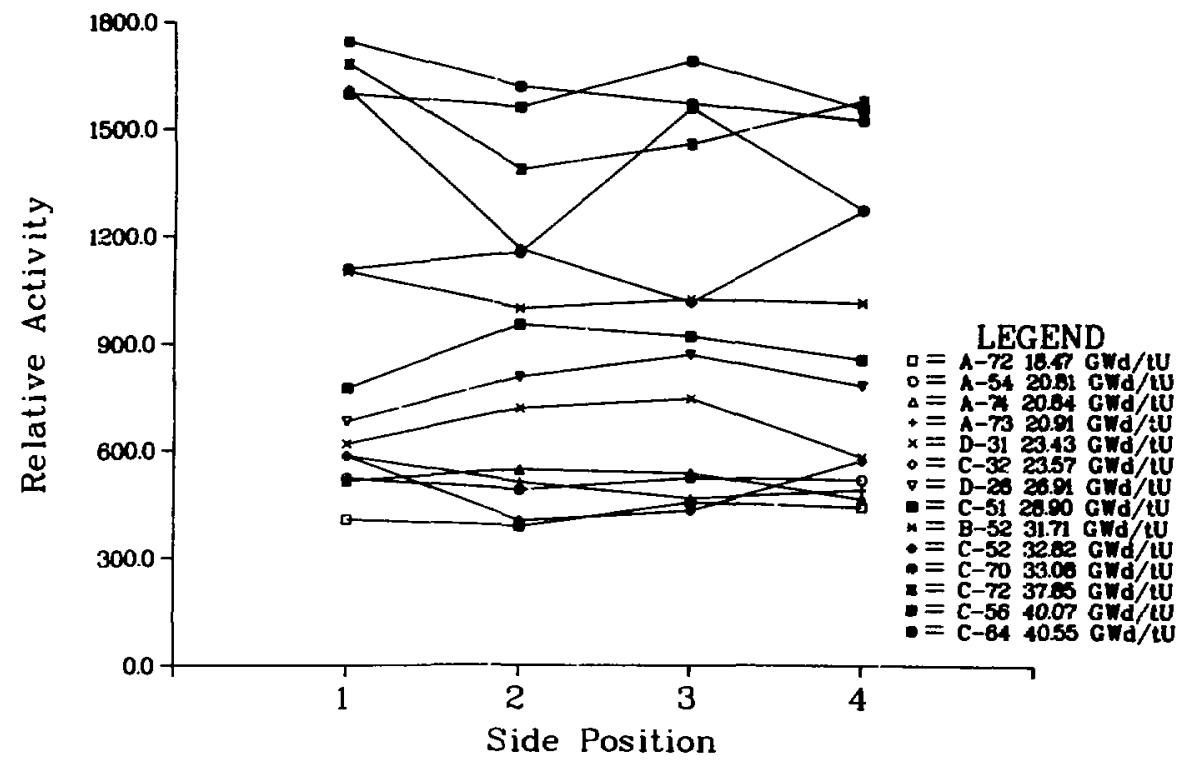

Fig. 20. Measured gross gamma-ray dose rates for each side of the 14 irradiated fuel assemblies.

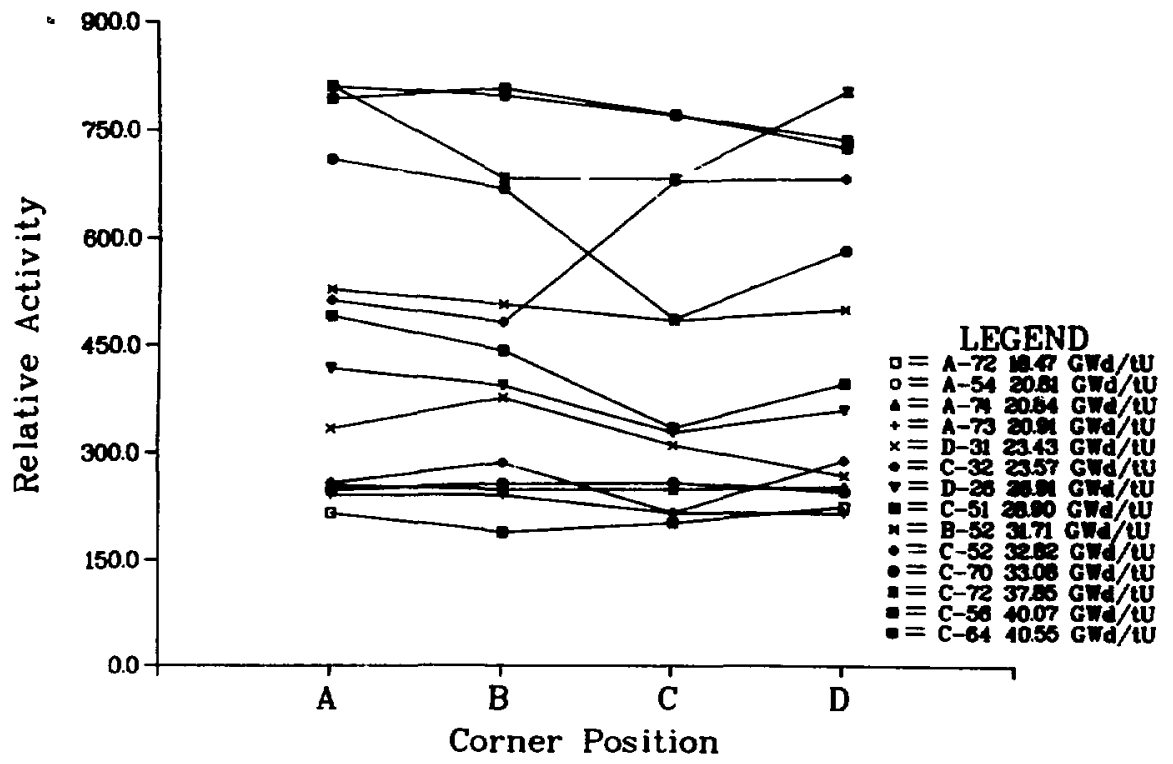

Fig. 21. Measured gross ganma-ray dose rates for each corner of the 14 irradiated fuel assemblies. 

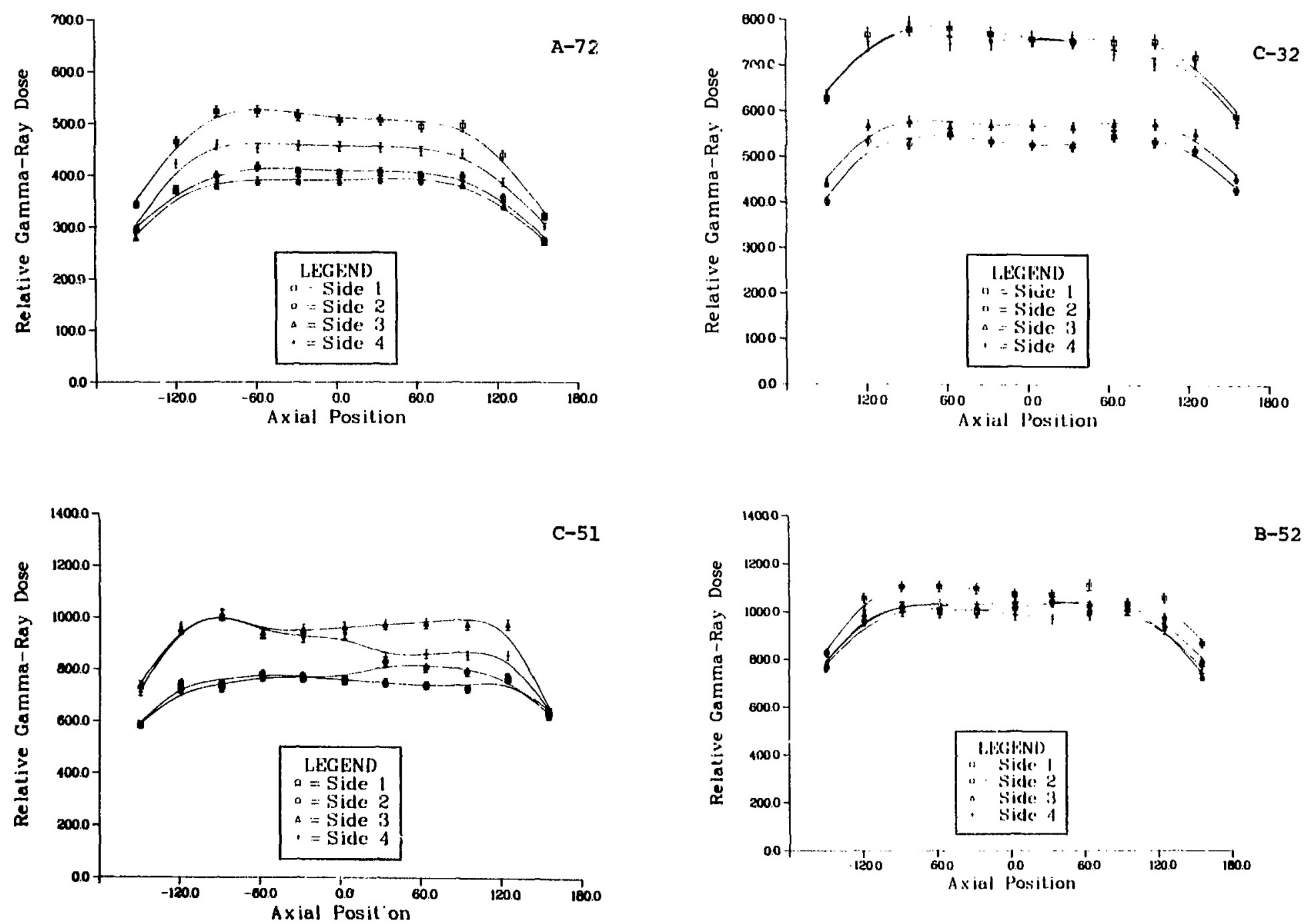

T1g. 22. Axial gross gama-ray profile for each side of the four fuel assemblies: A-72 (18.47 Gad/tU), $c-32(23.57 \mathrm{GNd} / \mathrm{tU}), c-51(28.91 \mathrm{GWd} / \mathrm{tU})$, and $B-52(31.71 \mathrm{GWd} / \mathrm{tU})$. 
assenblies. Figures 23 and 24 show the results for the side and corner measurements, respectively. Table XVIII gives the data plotted in Figs. 23 and 24. Table XIX shows the computed results using the least squares fitted line in Figs. 23 and 24, in which the side measurements give an average difference of 2.3\% and the corner measurements give an average difference of 3.38 . We stress that these measurenents are only a check of the internal consistency of a specific set of fuel assemblies. The number of days of cooling could be changed by a constant factor, and this analysis would not show any differences between the altered cooling times and the measured dose divided by the declared exposure values.

This analysis also assunes that the irradiation histories of the fuel assemblies are very similar tecause of the short half-lives of all the fission products except for ${ }^{137} \mathrm{Cs}\left(t_{1 / 2}=30.17 \mathrm{yr}\right)$. If a fuel assembly had an irregular irradiation history (for example, if it had been in the core for two cycles and out for two cycles followed by one more cycle in the core), Its gama dose as a function of cooling time would be significantly different from a fuel assembly in for three consecutive cycles. The contributions from ${ }^{144} \mathrm{Ce-Pr}$ (284.5 days), ${ }^{106} \mathrm{Ru}-\mathrm{Rh}$ ( 366.4 days), and ${ }^{134} \mathrm{Cs}(2.062 \mathrm{yr}$ ) for the first two cycles would be much lower for the fuel assembly with the irregular irradiation history than for the fuel assembly with the constant irradiation history.

\section{F. Position Sensitivity for the Square-Ring Detector}

The sensitivity of the gross gama-ray measurements to the relative positions of a fuel asseably within the square-ring detector was determinad by positioning the B-52 fuel assembly at 11 different locations and wasuring the outputs of the four ion chambers (Table $\mathrm{x}$ ). The total dose masurements varied by an average of less than $18(0.62)$ for the set. Comparable variation. in the neutron mesourements were 3.78. However, the effect on the burnup results 1s similar ( 218 ) because of the neutron power functioual relationship relative to the exposure. Because the gross gama-ray signal is attenunted much lese than is the neutron signal for the sane thickness of water, positioning is less critical for these wasurements. 


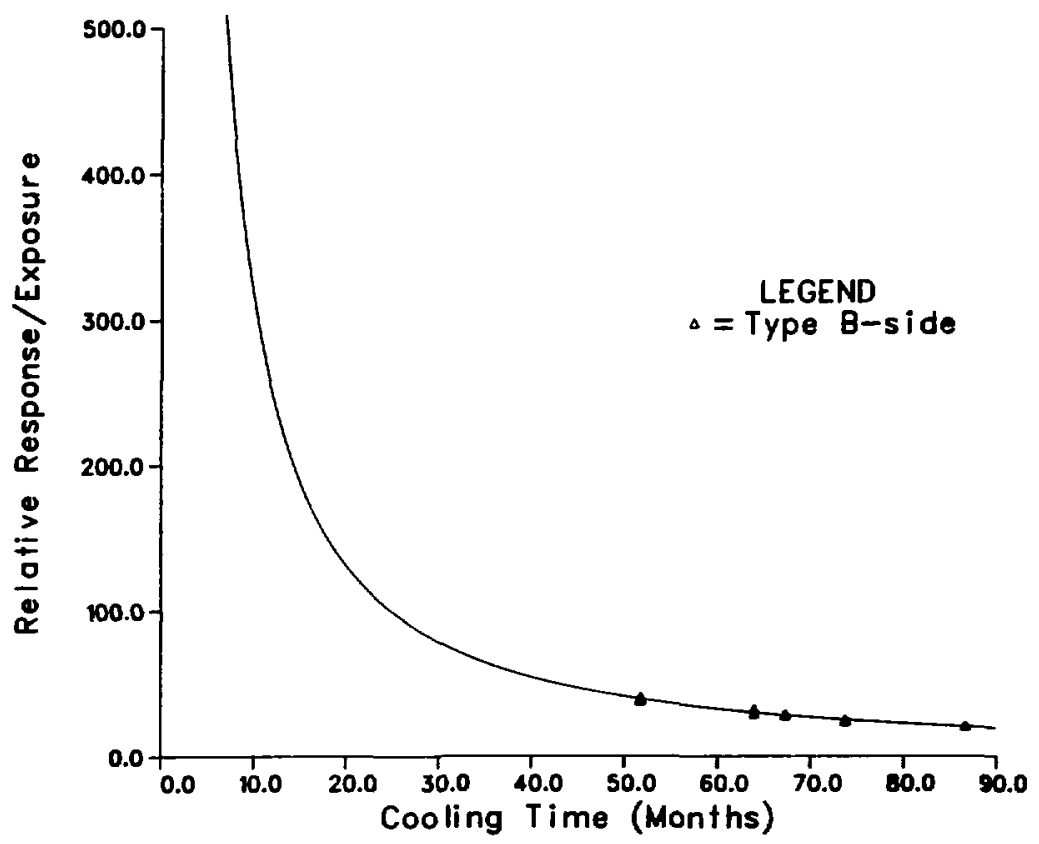

Fig. 23. Gross gamma-ray dose/exposures vs cooling tine for the set of 14 fuel assemblies using the square-ring detector. (Refer to Fig. 3 for calculated response.)

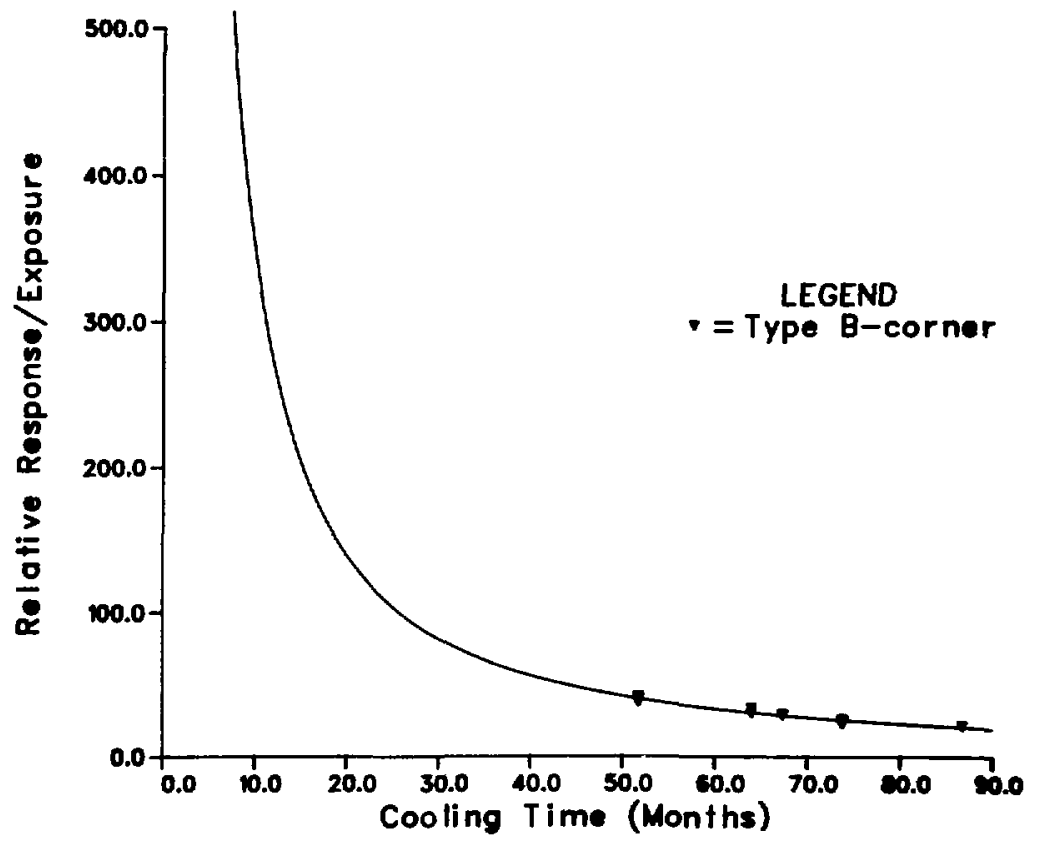

Fig. 24. Gross gama-ray dose/exponure ve cooling time for the cet of 14 fuel assemblies using the corner V-antector. (Dacer to FIg. 3 for calculated responee.) 
TABLE XVIII

RELATIVE GAMYA-RAY MEASUREMENTS OF FUEL ASSEMBLIES

\begin{tabular}{|c|c|c|c|c|c|c|}
\hline \multirow{3}{*}{$\begin{array}{l}\text { Fuel } \\
\text { Assembly }\end{array}$} & \multicolumn{2}{|c|}{ Declared } & \multirow[b]{2}{*}{ Measured } & \multirow[b]{2}{*}{ Lose ${ }^{a}$} & \multirow{2}{*}{\multicolumn{2}{|c|}{ Dose/Exposure }} \\
\hline & \multirow{2}{*}{$\begin{array}{l}\text { Exposure } \\
\text { (GWd/tU) } \\
\end{array}$} & \multirow{2}{*}{$\begin{array}{l}\text { Cooling } \\
\text { Time } \\
\text { (Days) } \\
\end{array}$} & & & & \\
\hline & & & side & Corner & Side & Corner \\
\hline$A-72$ & 18.47 & 2445 & 1697 & 828 & $91 \cdot 9$ & 44.8 \\
\hline$A-54$ & 20.81 & 2445 & 2058 & 1006 & 98.9 & 48.3 \\
\hline$A-74$ & 20.84 & 2445 & 2067 & 1002 & 99.2 & 48.1 \\
\hline$A-73$ & 20.91 & 2445 & 2057 & 911 & 98.4 & 43.6 \\
\hline$D-31$ & 23.43 & 2049 & 2667 & 1292 & 113.8 & 55.1 \\
\hline$c-32$ & 23.57 & 2638 & 1997 & 948 & 84.7 & 40.2 \\
\hline$D-26$ & 26.91 & 2049 & 3146 & 1504 & 116.9 & 55.9 \\
\hline$c-51$ & 28.90 & 1947 & 3513 & 1577 & 121.9 & 54.6 \\
\hline$B-52$ & 31.71 & 1947 & 4143 & 2023 & 130.7 & 63.8 \\
\hline$c-52$ & 32.82 & 1575 & 5066 & 2361 & 154.4 & 71.9 \\
\hline$c-70$ & 33.08 & 1575 & 5101 & 2452 & $154 \cdot 2$ & 74.1 \\
\hline$c-72$ & 37.85 & 1575 & 6115 & 2984 & 161.6 & $78 \cdot 8$ \\
\hline$c-56$ & 40.07 & 1575 & 6409 & 3106 & 159.9 & 77.5 \\
\hline$c-64$ & 40.55 & 1575 & 6464 & 3123 & 159.4 & 77.0 \\
\hline
\end{tabular}

$a_{\text {Relative units for all four sides or corners. }}$

VI. CONCLUSIONS MND RECOMNENDATIONS

This report concentrated on the evaluation of nondestructive techniques used to verify rapidly the operator-declared values for exposures and to rerify the consistency of the declared cooling times. We evaluated using gross gamaray and neutron measurement techniques to provide the inspector with the capability to verify spent-fuel assemblies. These accurate and timaly masurements can be performed with alnimal interference to the facility operator. The value of such measurement: should be considered in the context of the entire inspection process. For exanple, these techniques can be used with iten counting or Cerenkov light masurements to improve the level of verification presently available to the IAEA inspection. 
TRBLE XIX

RESULTS OF COOLING TIME CONSISTENCY CALCULATIONS

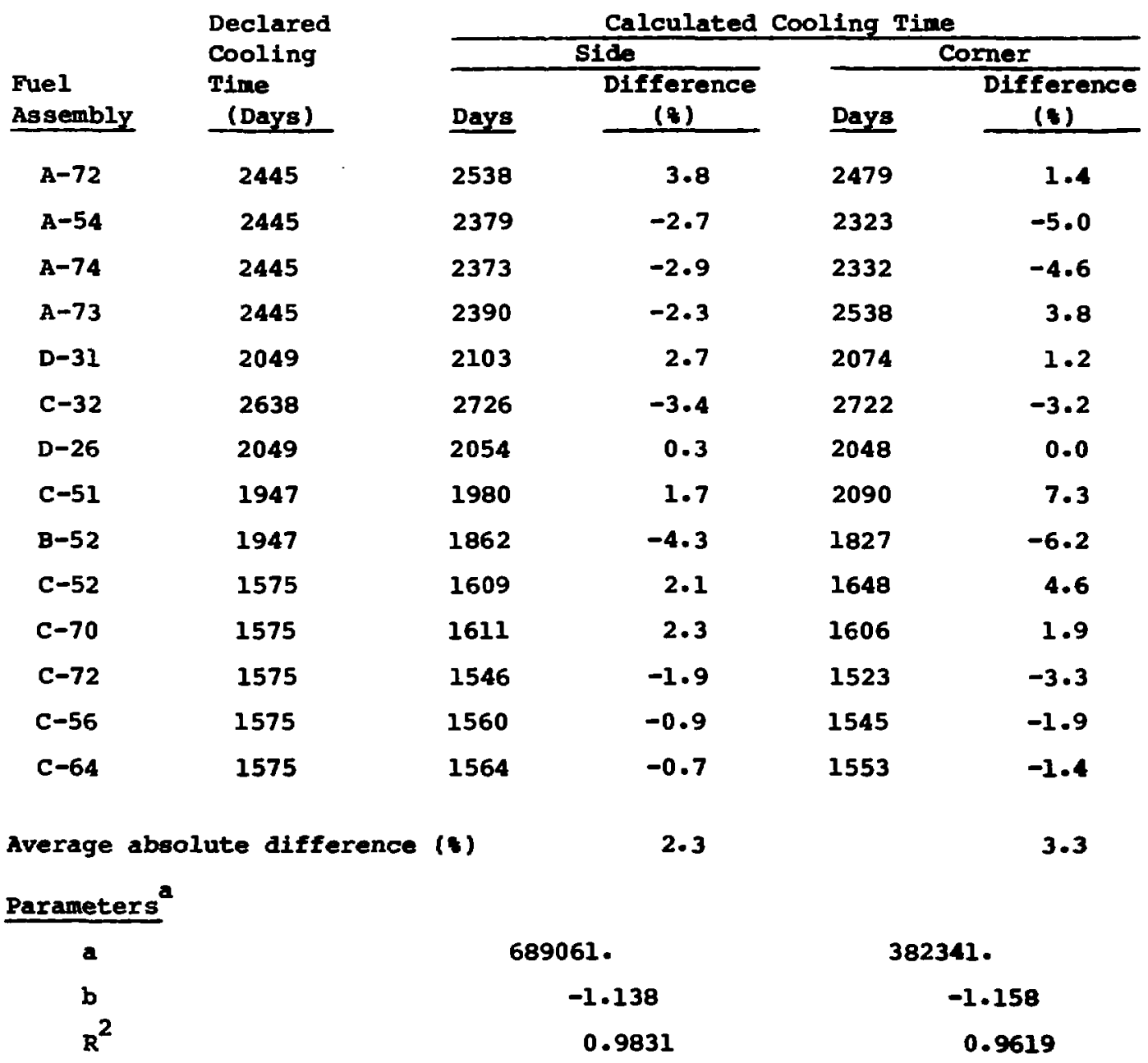

Equation used to approximate dose rate/exposure vs cooling tine

$$
\frac{\mathrm{DR}}{\mathrm{EXP}}=\mathbf{a} \times \mathrm{T}^{\mathbf{b}}
$$

$a_{R}{ }^{2}$ is the correlation coefficient. When multiplied by 100 , it represents the percentage of the total man variation explained by the regreasion. 
TABIE XX

POSITION SENSITIVITY FOR GROSS GAMMA-RAY MEASUREMENTS USING THE SQUARE-RING DETECTOF

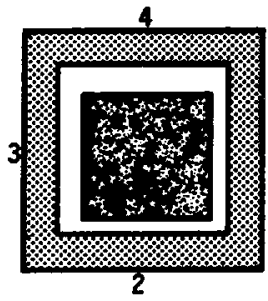

Side 152.5 Side $2 \quad 47.5$ 1 side $3 \quad 46.3$ side 46.3 Total 192.6

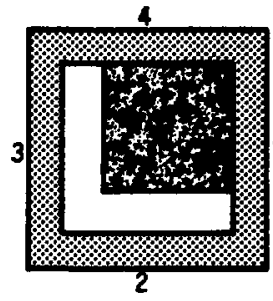

side 161.9 Side $2 \quad 37.9$ 1 Side $3 \quad 39.4$ side 457.5 Total 196.3

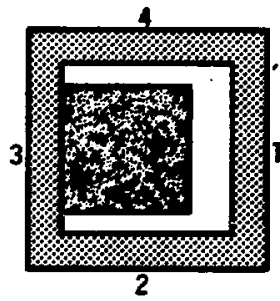

Side $1 \quad 41.6$ $\begin{array}{lll}\text { Side } 2 & 43.8\end{array}$ Side 361.3 Side 48.1 Totel 193.8

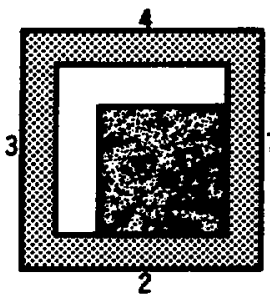

Side 161.3 Side $2 \quad 55.6$ Side 33.7 Side $4 \quad 39.4$ Total 195.1

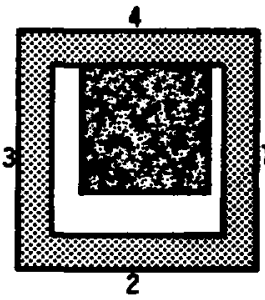

side 152.5 side 237.9 Side $3 \quad 46.6$ Side $4 \quad 58.8$ Motal 195.8

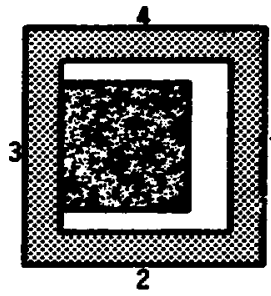

Side I 48.1 side 2 48.1 side $3 \quad 52.5$ side 45.6 Total 194.3

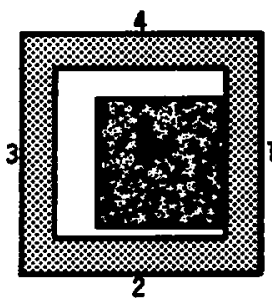

Side $1 \quad 62.5$ side $2 \quad 48.8$ side $3 \quad 39.4$ side 44.4 Totel 195.1

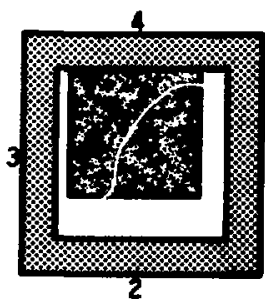

Side $1 \quad 41.3$ side 237.1 side $3 \quad 58.8$ side 458.1 Total 195.2

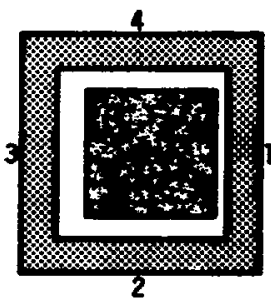

side 161.1 Side 249.1 side $3 \quad 41.6$ side 44.4 Total 194.4

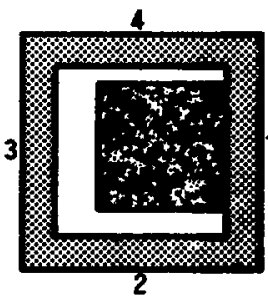

side 162.5 side 239.4 side 339.4 side 455.6 Total 195.1

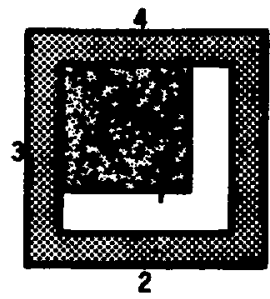

side 141.1 side 236.8 1 side 361.3 side 458.1 Total 196.2 
Passive neutron measurements can determine rapidly the relative exposures of irradiated fuel assenblies with an average absolute difference of approximately 4\%, using the power functional relationship correlating exposure with the measured counting rates. Similar results are obtained if either the sides or corners of the fuel. assemblies are measured. Using fission chambers horizontal to the principal axis of the fuel assenbly may reduce the effect: of burnup gradients across the fuel assembly: because vertical detectors measure fewer pins. Using either detector configuration, 18 counting statistics can be obtained within 10 to $30 \mathrm{~s}$ for fuel assemblies with 18.4- to 40.6-GNd/to exposures and from 1575 to 2638 days of cooling.

Gross gamma-ray dose measurements can be used to deternine rapidiy the consistency of a set of declared cooling times by plotting the dose/exposure vs declared cooling times and inspecting the plot for data points that do not lie within the expected limits. This is a qualitative measurement; hovever, it is a convenient method for obtaining information about the declared cooling times.

Two detector designs that could be used by IAEA inspectors for the rapid verification of spent-fuel assemblies are shown in Fig. 25 . One design consists of a single set of detectors that would measure the signals canating from only one side of the fuel assembly. The other design contains two sets of detectors placed horizontally on opposita sides of the fuel ascembly. This detector arrangement would partly compensate for exposure gradients acrose the fuel assembly, as gradients of 20 to 30 have been measured in this investigation. As discussed in Sec. IV.C.5, two detectors placed on opposite sides of the fuel assembly would give slightly better results than just one set of detectors. However, the inprovenent would only be about 1\%, with both detector designs providing results in the 5 t range.

Both the neutron and gross gama-ray measurements can be obtained rapidly using either detector design dewcribed and the IOA-1 electronics unit. To perform the measurements, the fuel assemblies wast be raised until the top half of the assembly is out of the storage racks at the botton of the pool. neasuring these two signatures gives a significantly higher level of verification of the inspection than does item counting or Cerenkov light masurements. Isain we stress that any inspection procedure wat consist of a combination of contaiment/surveillance accounting and masurement technique to provide an wocoptable level of verification within the mappower and tim restrictions. 

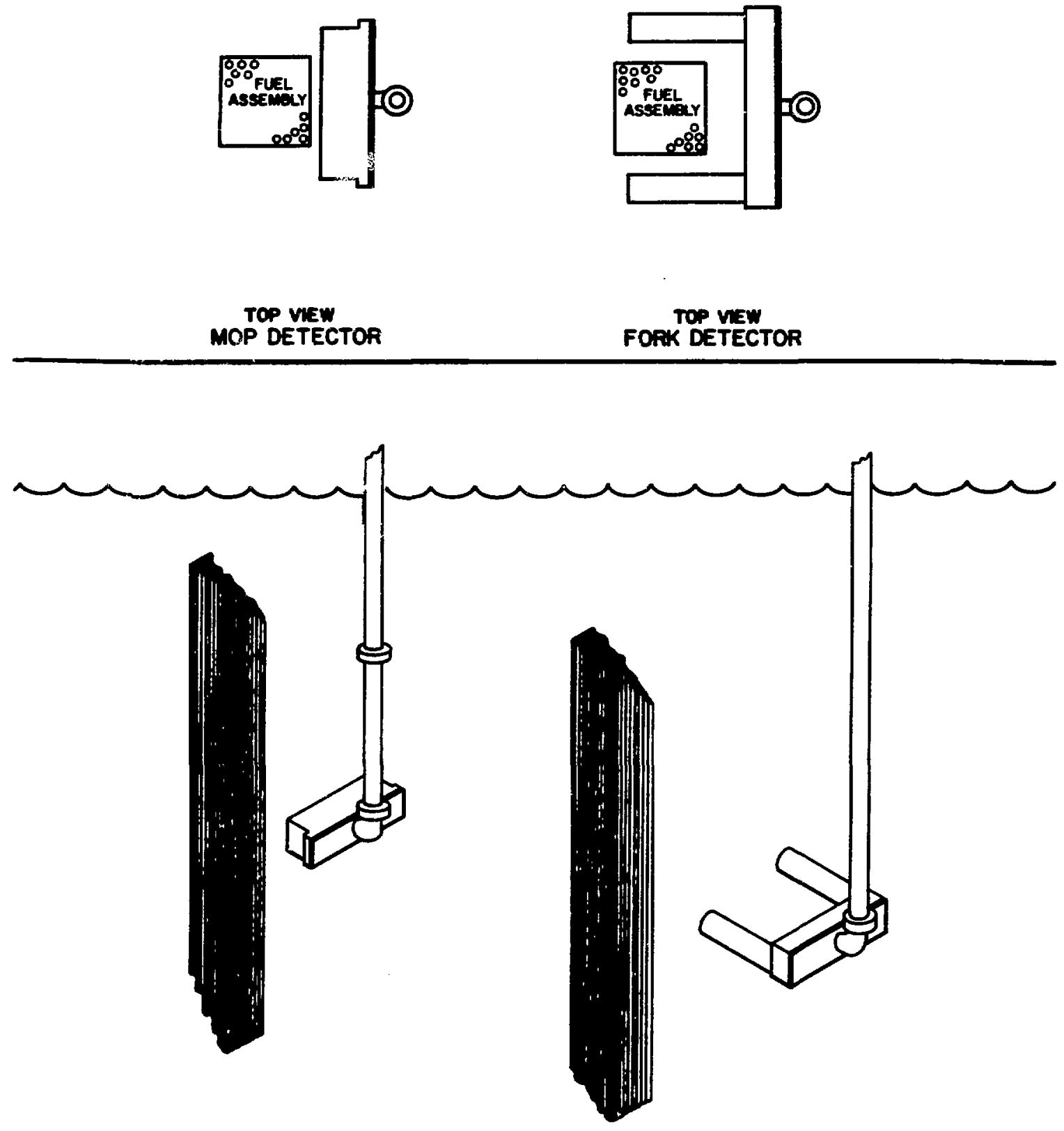

SIDE VI" MOP DETECTOR
SHeE VISW

FORK DETECTOR

Fig. 25. Two detector designs for the rapid verification of spent-fuel assemblies. 


\section{ACKNONLEGMENTS}

We extend our gratitude to F. A. Duran and O. R. Holbrooks for their support throughout the measurenent exercise. We also appreciate the assistance of P. M. Rinard in preparing the curves relating the gama dose rate to the declared exposure and cooling time values. General Electric personnel at the Morris operation Spent-Fuel storage Facility provided expert assistance during the measurements. He also gratefully acknowledge the support of the International Safeguards office at Brookhaven National Laboratory and the Do: office of Safeguards and Security.

\section{REFERENCES}

1. "Non-Proliferation and International Safeguards," International Atomic Energy Agency report IAfa-575 (1978).

2. Whe structure and content of Agreements between the Agency and states Required in Connection with the Treaty on the Non-Proliferation of luclear Weapons," International Atonic Energy Agency report INFCIRC/153 (corrected) (June 1971 ).

3. H. Gruen, "Designing IAER Safeguards Approaches," Nucl. Mater. Manage. IX, 14-24 (July 1980).

4. "IABR Contribution to IMLCE--The Present Status of InsA Safeguards on thuclear Fuel Cycle Facilities," International Atonic Energy Agency report INFCE/SEC/11 (February 1979).

5. "InEA Safeguards Technical Manual, Introduction, Part $\mathrm{A}^{*}$ International Atonic Energy hgency report IAx-174 (1976).

6. D. D. Cobb, H. H. Dayem, and R. J. Dietz, "Preliminary Concepts: safeguards for Spent IIght-Nater Reactor Fuele," Ios Rlamos Scientific Iaboratory report LA-7730-MS (June 1979).

7. "Advisory Group Meeting on Kathods and Techniques for kDA safeguards Masurements of Power Reactor Spent Fuel," International Atonic Inergy agency report MG-241, Vienna, October 29-November 2, 1979.

8. E. J. Dowdy, H. Micholeon, and J. T. Celdwe11, "Irradiated Fuel Monitoring by Cerenkov Glow Intensity Neasuremes," Ios alamos Scientifle Inboratory report LA-7838-iss (ISPO-61) (September 1979).

9. N. Nicholson and I. J. Dowdy, "Irradiated Fuel Jxanination Using the Cerenkov Technique," Ios Alanos Mational Inboratory report In-0767-is (karch 1981). 
10. C. E. Moss and D. M. Lee, "Gross Gama-Ray Measurements of Light Water Reactor Spent-Fuel Assemblies in Underwater Storage Arrays," Los Alanos Scientific Laboratory report LA-8447 (ISPO-132) (Decenber 1980).

11. D, M. Lee, J. R, Phillips, S.-T. Hsue, K. Kaieda, J. K. Halbig, E. G. Hedina, and C. R. Hatcher, "A New Approach to the Examination of LWR Irradiated Fuel Assemblies Using Simple Gas Chamber Techniques," Los Alanos Scientific Laboratory report LA-7655-MS (ISPO-48) (March 1979).

12. P. M. Rinard, "Irradiated Fuel Inspection in a Storage Pond with Ho Fuel Movenent and an Uncollimated Detector," Los Alamos Scientific Laboratory report LA-8463-MS (ISPO-110) (July 1980).

13. S. T. Hsue, J. E. Stewart, K. Kaieda, J. K. Halbig, J. R. Phillips, D. M. Lee, and C. R. Hatcher, "Passive Neutron Assay of Irradiated Muclear Fuels," Los Alamos Scientific Laboratory report LA-7645-ins (Pebruary 1979).

14. J. R. Phillips, G. E. Bosler, J. K. Halbig, S. F. Klosterbuer, D. M. Lee, and H. O. Menlove, "Neutron Measurement Techniques for the Nondestructive Analysis of Irradiated Fuel Assemblies," Los Alanos National Laboratory report IA-9002-kS (ISPO-156) (November 1981).

15. T. N. Dragnev, "Intrinsic Self-Calibration of Non-Destructive Gana Spectrometric Heasurements (Determination of $U$, Pu, and $\mathrm{Am-241}$ Isotopic Ratios)," International Atomic Energy Agency report IAcMSTR-60 (Vienna 1976).

16. J. R. Phillips, J. K. Halbig, D. M. Lee, S. E. Beach, T. R. Bement, E. Dermendjlev, C. R. Hatcher, K. Kaieda, and E. G. Medina, "Application of Nondestructive Gama-Ray and Neutron Techniques for the Safeguarding of Irradiated Fuel Materials," Los Mlanos Scientific Laboratory report LA-8212 (ISPO-77) (Kay 1980).

17. S. T. Hsue, C. R. Hatcher, and K. Kaieda, "Cooling Time Deternination of Spent Fuel," Nucl. Mater. Manage. VIII, 356-367 (fall 1979).

12. J. K. Halbig and S. F. Klosterbuer, "Portable Spent-Fuel Gama-Ray and Neutron Detector Electronics User Manual," to be published as LA-8707-H.

19. P. I. Fedotov, H. H. Kazarinov, and A. A. Voronkov, "The Use of lieutron Scanning wethod for Analysia of Spent VVER Fuel in Safeguarding Systea," Proc. 3rd Ann. ISARDA Syrp. Safeguards Nucl. Kater. Manage., Karleruhe, Federal Republic of Gernany, 1981.

20. D. D. Cobb, J. R. Phillips, G. E. Bosler, G. W. Eccleston, J. K. Halbig, C. R. Hatcher, and S-T. Houe, MondestructIve Verification and Masa SYstems for Spent Fuels," Los Mlamos National Iaboratory report In-904l Vol. 1 (April 1982). 